\title{
Green Synthesis and Characterization of
}

\section{Carboxymethyl Cellulose Fabricated Silver-Based Nanocomposite for Various Therapeutic Applications}

\author{
Muhammad Arif Asghar (iD) \\ Rabia Ismail Yousuf (D) $^{\prime}$ \\ Muhammad Harris Shoaib (D) \\ Muhammad Asif Asghar (iD ${ }^{2}$ \\ Mehrukh Zehravi ${ }^{3}$ \\ Ahad Abdul Rehman ${ }^{4}$ \\ Muhammad Suleman Imtiaz ${ }^{5}$ \\ Kamran Khan ${ }^{5}$ \\ 'Department of Pharmaceutics, Faculty of \\ Pharmacy and Pharmaceutical Sciences, \\ University of Karachi, Karachi, Pakistan; \\ ${ }^{2}$ Food and Feed Safety Laboratory, Food \\ and Marine Resources Research Centre, \\ PCSIR Laboratories Complex, Karachi, \\ Sindh, Pakistan; ${ }^{3}$ Department of Clinical \\ Pharmacy, College of Pharmacy for Girls, \\ Prince Sattam Bin Abdul Aziz University, \\ Al-Kharj, Kingdom of Saudi Arabia; \\ ${ }^{4}$ Department of Pharmacology, Institute \\ of Pharmaceutical Sciences, Jinnah Sindh \\ Medical University, Karachi, Pakistan; \\ ${ }^{5}$ Department of Pharmaceutics, Institute \\ of Pharmaceutical Sciences, Jinnah Sindh \\ Medical University, Karachi, Pakistan
}

Correspondence: Rabia Ismail Yousuf; Muhammad Harris Shoaib Department of Pharmaceutics, Faculty of Pharmacy and Pharmaceutical Sciences, University of Karachi, Karachi, Pakistan Email rabia_pharmaceutics@yahoo.com; harrisshoaib2000@yahoo.com;

mhshoaib@uok.edu.pk
Purpose: The current study proposed the simple, eco-friendly and cost-effective synthesis of carboxymethyl cellulose (CMC) structured silver-based nanocomposite (CMC-AgNPs) using Syzygium aromaticum buds extract.

Methods: The CMC-AgNPs were characterized by ultraviolet (UV) spectroscopy, scanning electron microscopy (SEM), transmission electron microscopy (TEM), X-ray diffraction (XRD), Fourier transmission infra-red (FTIR), energy-dispersive X-ray (EDX), and dynamic light scattering (DLS) techniques. The synthesized nanocomposites were evaluated for their bactericidal kinetics, in-vivo anti-inflammatory, anti-leishmaniasis, antioxidant and cytotoxic activities using different in-vitro and in-vivo models.

Results: The spherical shape nanocomposite of CMC-AgNPs was synthesized with the mean size range of $20-30 \mathrm{~nm}$, and the average pore diameter is $18.2 \mathrm{~nm}$ while the mean zeta potential of $-31.6 \pm 3.64 \mathrm{mV}$. The highly significant $(P<0.005)$ antibacterial activity was found against six bacterial strains with the ZIs of 24.6 to $27.9 \mathrm{~mm}$. More drop counts were observed in Gram-negative strains after $10 \mathrm{~min}$ exposure with CMC-AgNPs. Significant damage in bacterial cell membrane was also observed in atomic force microscopy (AFM) after treated with CMC-AgNPs. Nanocomposite showed highly significant antiinflammatory activity in cotton pellet induced granuloma model (Phase I) in rats with the mean inhibitions of $43.13 \%$ and $48.68 \%$ at the doses of 0.025 and $0.05 \mathrm{mg} / \mathrm{kg}$, respectively, when compared to control. Reduction in rat paw edema (Phase II) was also highly significant (0.025 mg/kg; 42.39\%; $0.05 \mathrm{mg} / \mathrm{kg}, 47.82 \%)$. At dose of $0.05 \mathrm{mg} / \mathrm{kg}$, CMC-AgNPs caused highly significant decrease in leukocyte counts $(922 \pm 83)$, levels of CRP $(8.4 \pm 0.73$ $\mathrm{mg} / \mathrm{mL})$, IL-1 $(177.4 \pm 21.3 \mathrm{pg} / \mathrm{mL})$, IL-2 $(83.7 \pm 11.5 \mathrm{pg} / \mathrm{mL})$, IL-6 $(83.7 \pm 11.5 \mathrm{pg} / \mathrm{mL})$ and TNF- $\alpha(18.3 \pm 5.3 \mathrm{pg} / \mathrm{mL})$ as compared to control group. CMC-AgNPs produced highly effective anti-leishmaniasis activity with the viable Leishmania major counts decreased up to $36.7 \%$ within $24 \mathrm{~h}$, and the $\mathrm{IC}_{50}$ was found to be $28.41 \mu \mathrm{g} / \mathrm{mL}$. The potent $\mathrm{DPPH}$ radical scavenging potential was also observed for CMC-AgNPs with the $\mathrm{IC}_{50}$ value of 112 $\mu \mathrm{g} / \mathrm{mL}$. Furthermore, the cytotoxicity was assessed using HeLa cell lines with the $\mathrm{LC}_{50}$ of $108.2 \mu \mathrm{g} / \mathrm{mL}$.

Conclusion: The current findings demonstrate positive attributes of CMC fabricated AgNPs as a promising antibacterial, anti-inflammatory, anti-leishmaniasis, and antioxidant agent with low cytotoxic potential.

Keywords: silver nanoparticles, Syzygium aromaticum, carboxymethyl cellulose, green synthesis, biological applications 


\section{Graphical Abstract}

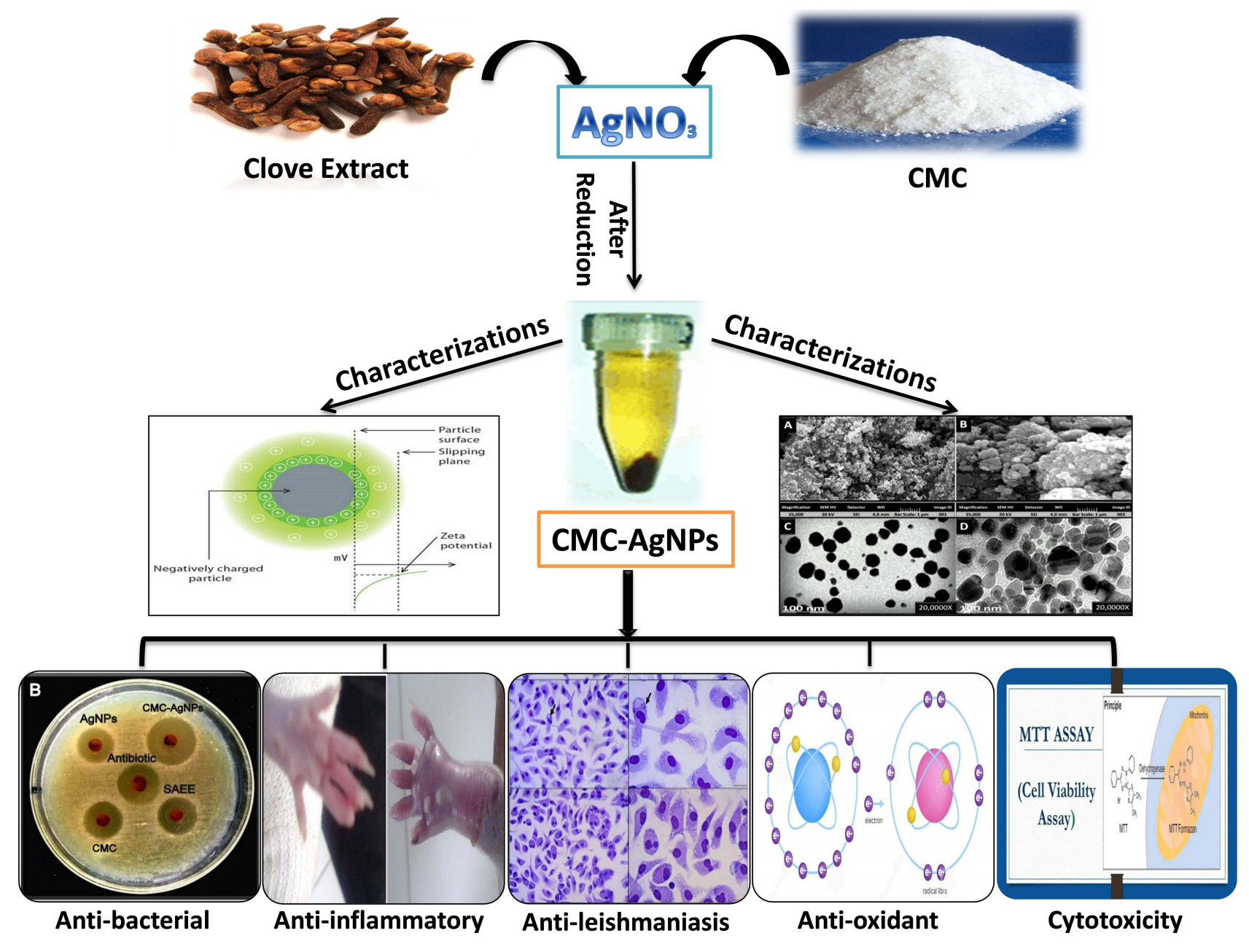

\section{Introduction}

Green synthesis of nanoparticles (NPs) is the most emerging and widely used technique due to ecofriendly and cost-effective synthetic scheme over classical synthesis methods. In recent times, NPs have been used as diagnostic agents, therapeutic agents, fluorescent labels, and transfection labels. ${ }^{1-3}$ Silver nanoparticles (AgNPs) specifically have unique biological and physicochemical characteristics and are being used in different biological, photovoltaic and different chemical products. ${ }^{4-6}$ To date, silver nanoparticles (AgNPs) are considered more attractive and economical in various biomedical applications due to their excellent antibacterial activity as compared to other metallic NPs. It shows a wide array of applications as conductive nanofluids, biosensors, and antimicrobial agents, in biomedical fields. ${ }^{7-10}$
In addition, nanocomposites of different polymers with inorganic metals are gaining scientific importance and are the focus of attraction. Previously, it was observed that the incorporation of metal NPs into the polymer matrix could improve the performance of synthesized nanocomposite at a lower cost. ${ }^{11-13}$ Silverbased nanocomposites have been synthesized after functionalization with a variety of cellulose containing polymers like chitosan, gelatin, polyacrylic acid, and guar gum. ${ }^{14-21}$ Nanocomposites are now widely used in various applications including automotive, packaging, aerospace, electronics, defense, semiconductors, energy, coatings, sports, medical, and healthcare. ${ }^{22,23}$ Today, one of the appealing research interests of scientists is to modify or surface functionalized nanomaterials in order to improve their particular physical-chemical and biological properties. ${ }^{24-26}$ 
Polysaccharides are bio-compatible, non-toxic, and biodegradable polymers and have been widely used in numerous biomedical fields such as drug delivery, cell imaging, electrochemical devices, and energy storage. ${ }^{27}$ Among all available water-soluble polysaccharides, carboxymethyl cellulose (CMC) is extensively used in medical, environmental, and agriculture industries due to its sustainable, renewable, and nontoxic properties. ${ }^{28,29}$ It is a carbohydrate polymer having a cellulose backbone with carboxymethyl groups bound with hydroxyl groups of the glucopyranose monomers. ${ }^{30}$ It has been reported that $\mathrm{CMC}$ acts as a stabilizing and reducing agent in the synthesis of AgNPs. ${ }^{31}$ Nanocellulose is non-toxic, biodegradable and biocompatible with no adverse effects on health and the environment. Due to their high aspect ratio, low thermal expansion coefficient, better tensile strength, good optical and mechanical properties, they are used in many applications like tenable hydrogels, paper making, coating additives, optically transparent films, food packaging, flexible screens and many others. It also find potential in biopharmaceutical applications such as in drug delivery and for fabricating temporary implants. Previously, researchers also have reported the antimicrobial, anti-inflammatory, and antioxidant activity of CMC as a nanocarrier. ${ }^{31-33}$ Recently, many researchers reported the synthesis of silver NPs using cellulose containing plant extracts and other compounds with highly significant therapeutic activities such as antioxidant, antibacterial, anticancerous and different photo catalytic applications. $^{34-37}$

Previously few studies reported the synthesis of CMC fabricated silver NPs through chemical reduction methods. ${ }^{38,39}$ However, there is no study available on the decoration of silver NPs with CMC via green route using Syzygium aromaticum buds extracts. In addition, no study reported the pharmacological and cytotoxic activities of CMC-based silver NPs. Hence, in continuation of our previous effort for the eco-friendly green synthesis of chitosan-based AgNPs, current research has focused on integrating AgNPs with another biocompatible polymer ie, CMC, along with Syzygium aromaticum buds extracts. ${ }^{14}$ This synthesized nanocomposite was evaluated for its antibacterial activity with time-killing kinetics, in-vivo anti-inflammatory, anti-leishmaniasis, and antioxidant potentials.

\section{Materials and Methods}

\section{Synthesis of Carboxymethyl Cellulose (CMC)-Based Silver Nanocomposite}

Green synthesis of AgNPs using Syzygium aromaticum ethanolic buds extract (SAEE) was described in our previous study in which SAEE was used as a reducing and capping agent. ${ }^{14}$ However, CMC-based silver nanoparticles (CMC-AgNPs) along with plant extract were synthesized according to the previously described method with some modifications. ${ }^{31}$ CMC-AgNPs were prepared by adding dropwise solution of SAEE $(10 \mathrm{mg} /$ $\mathrm{mL})$ and $\mathrm{CMC}(5 \mathrm{mg} / \mathrm{mL})$ to aqueous solution of $\mathrm{AgNO}_{3}(1 \mathrm{mmol} / \mathrm{L})$. In this AgNPs synthesis, CMC has also been used as a reducing and stabilizing agent. The prepared suspension was centrifuged at $10,000 \mathrm{rpm}$ for $30 \mathrm{~min}$, and the supernatant was separated, washed with deionized water, and assessed using a UV spectrophotometer for the successful synthesis of CMC-AgNPs. The change in color from silver to greenish-black also indicated the synthesis of CMC based AgNPs. Finally, the synthesized nanocomposite was cleaned with DI$\mathrm{H}_{2} \mathrm{O}$ three times to eliminate any free biological materials and then dried using a hot air oven at $65{ }^{\circ} \mathrm{C}$ for $12 \mathrm{~h}$ to obtain purified CMC-AgNPs. However, the degree of substitution (DS) value of CMC in synthesized nanocomposite was estimated from potentiometric titrations. $^{40}$

\section{Characterization of CMC-AgNPs Nanocomposite}

The optical properties and functionalization of $\mathrm{CMC}$ with AgNPs were evaluated using a UV-Vis Shimadzu UV-2600 spectrophotometer (Shimadzu Corporation, Tokyo, Japan) at a $200-700 \mathrm{~nm}$ wavelength range. The size and surface morphology of synthesized CMCAgNPs nanocomposite were assessed using the JSM 4380B scanning electron microscope (Joel, JSM 4380B Model, Japan) and JEM 2100F transmission electron microscope (Joel, JEM 300F Model, Japan). The crystalline nature of synthesized nanocomposites was analyzed using a Bruker's X-ray Diffractometer (Massachusetts, USA) with a graphite monochromator, $\mathrm{Cu}$ tube 
radiation $(\mathrm{k}=1.54184 \AA)$ and Lynxeye detector at 30 $\mathrm{kV}$ with $10 \mathrm{~mA}$ current. Measurements were taken over an angular range of $0.99^{\circ} \leq 2 \theta \leq 89.99^{\circ}$ with a counting time of $10 \mathrm{~s}$ and a scanning step of 0.05 . Divergence, receiving and scattered radiation slits were $1^{\circ}, 0.2 \mathrm{~mm}$ and $1^{\circ}$, respectively (Badawy et al 2018). Identification of functional groups and detection of silver ions in CMC-AgNPs nanocomposite were done using the Shimadzu IR-100 Fourier-transform infrared spectrophotometer (Shimadzu Corporation, Tokyo, Japan) in the wavelength range of $400-4000 / \mathrm{cm}$ and JSM 6380 energy-dispersion X-ray spectroscope (Joel, Tokyo, Japan) within the range of 0 and $10 \mathrm{kV}$, respectively. The dynamic light scattering (DLS) technique, along with particle size analyzer (Brookhaven Corporation, NY, USA), was used to measure the size and zeta potential of CMC-AgNPs. The obtained yield of the synthesized nanocomposite was measured with a PerkinElmer Optima 8300 ICP-OES analyzer (Shelton, USA). ${ }^{41,42}$

\section{Antibacterial Activity \\ Determination of Zones of Inhibitions}

The standard bacterial strains including three Grampositive (Staphylococcus aureus [ATCC 4712], Streptococcus mutans [ATCC 5656] and Staphylococcus epidermidis [ATCC 1035]) and three Gram-negative (Klebsiella pneumoniae [ATCC 0892], Salmonella typhi [ATCC 7421] and Pseudomonas aeruginosa [ATCC 0343]) were received from the supplier of Sigma-Aldrich, USA. The antibacterial potential of SAEE, CMC, AgNPs, CMC-AgNPs, and standard antibiotics (Amoxicillin was used against Gram-positive strains, while Cefoxitin was tested against Gram-negative strains) was analyzed using the Oxford cup method as described in our previous studies. ${ }^{43,44}$ Bacterial dilutions of each bacterial strain were made as McFarland turbidity standard $\left(10^{6} \mathrm{cfu} / \mathrm{mL}\right)$ using the nutrient broth, and UV visible spectrophotometry technique was used to determine the turbidity of each dilution. Each bacterial strain was spread, and sterile five diffusion cups were placed on each nutrient agar plate after perforation. Then, $0.1 \mathrm{~mL}$ aqueous solution of each antibacterial agent with the concentrations of $5,000 \mu \mathrm{g} / \mathrm{mL}$ of SAEE; $500 \mu \mathrm{g} / \mathrm{mL}$ of CMC, AgNPs, and CMC-AgNPs (Eq. to $50 \mu \mathrm{g}$ ) and $300 \mu \mathrm{g} / \mathrm{mL}$ (Eq. to $30 \mu \mathrm{g}$ standard disc) of each antibiotic was poured into five different cups of each respective plate. Diffusion was made to occur in each plate after allowing it to stand for $60 \mathrm{~min}$ and then incubated for $24 \mathrm{~h}$ at $37 \pm 2{ }^{\circ} \mathrm{C}$. The inhibition zones were measured in millimeters using the digital Vernier caliper, and this experiment was performed three times.

\section{Determination of Minimum Inhibitory Concentrations (MICs) and Minimum Bactericidal Concentrations (MBCs)}

The MIC values of each antibacterial agent were determined using the broth dilution method. ${ }^{45}$ The serial dilutions of SAEE (from 30,000 to $1000 \mu \mathrm{g} / \mathrm{mL}$ ), CMC, AgNPs and CMC-AgNPs (512 to $1 \mu \mathrm{g} / \mathrm{mL}$ ) were used for the estimation of MICs values in nutrient broth. The concentration of all culture strains was adjusted to McFarland turbidity standard $\left(10^{6} \mathrm{cfu} / \mathrm{mL}\right)$. After incubation, an ELISA reader (Infinite 200; Chicago, USA) was used to measure the optical densities (ODs) of each plate at $600 \mathrm{~nm}$. The MICs of each antibacterial agent were measured three times and given as their mean $\pm \mathrm{SD}$. In addition, the MBC of each antibacterial agent was determined by plating the already incubated test samples on nutrient agar plates. After $24 \mathrm{~h}$ incubation period at $37{ }^{\circ} \mathrm{C}$, viable cell colonies were counted in each plate. ${ }^{46}$

\section{Bacterial Killing Kinetics}

The bacterial killing kinetics assay of CMC-AgNPs nanocomposite was performed according to our previously reported method. ${ }^{47}$ The assay was conducted at the CMC-AgNPs nanocomposite concentrations equal to the MBC of each bacterial strain. Prior to the addition of CMC-AgNPs, the cells of each bacterial strain were grown to logarithmic phase in nutrient broth for $6 \mathrm{~h}$ with a concentration of $1 \times 10^{8} \mathrm{cfu} / \mathrm{mL}$. Then, each bacterial culture was incubated in a benchtop incubator shaker (Amerex Instruments, Inc., USA) at $37{ }^{\circ} \mathrm{C}$, and a culture sample was drawn after every $5 \mathrm{~min}$ interval. Viable cell counts were measured by spreading a drawn sample onto the nutrient agar plates. Then, plates were incubated for $48 \mathrm{~h}$ at ambient temperature, and bacterial colonies were counted. The bacterial killing kinetic curve was constructed between the viability of cells in cfu/mL and time in $\min$. 


\section{Atomic Force Microscopy (AFM) Study}

The morphological changes in bacterial cells and the killing mechanism were assessed on both Gram positive and negative strains via the AFM technique. A volume of $1 \mathrm{~mL}$ gelatin $(10 \%)$ was used for the preparation of mica slides. The treated cultures of $S$. aureus and $K$. pneumonia were harvested from microtiter and were then placed on the slides prepared with the polylysine mica. After the inoculation, bacterial strains were dried at room temperature. The prepared slides were observed on AFM (Veeco-Dimension 3100) for morphological changes in bacterial strains. ${ }^{48}$

\section{Anti-Inflammatory Activity Animals}

The anti-inflammatory activity of SAEE, CMC, AgNPs, and CMC-AgNPs nanocomposite was evaluated on Sprague Dawley rats of both sexes, which were obtained from the animal house of the Pakistan Council of Scientific and Industrial Research (PCSIR). The average body weight of received animals was $225 \pm 42 \mathrm{~g}$. The consent form was filled and submitted to the in charge of the animal house. Animals of both control and tested groups were kept at a controlled temperature of $25^{\circ} \mathrm{C} \pm$ $2{ }^{\circ} \mathrm{C}$ and $60 \pm 5 \%$ humidity in plastic cages in a $12 \mathrm{~h}$ light-dark cycle. Animals were divided into ten groups, with ten rats in each group. After study completion, medetomidine $(2 \mu \mathrm{g} / \mathrm{kg})$ was administered intravenously as a sedating agent, and the animals were euthanatized using the cervical dislocation method. ${ }^{49}$ The guidelines provided by National Advisory Committee for Laboratory Animal Research (NACLAR) were adopted for animal handling. ${ }^{50}$ Moreover, the study was approved by the local departmental ethical committee of Jinnah Sindh Medical University with the approval number JSMU/IRB/2019/286.

\section{Dosage Protocol}

All test solutions were administered orally once a day. Distilled water was administered to the 1st group and considered as control; SAEE was given to the 2nd and 3rd groups in two different doses, ie, 125 and $250 \mathrm{mg} / \mathrm{kg}$. At the doses of $0.025 \mathrm{mg} / \mathrm{kg}$ and 0.05 $\mathrm{mg} / \mathrm{kg}, \mathrm{CMC}$ was administered to 4 th and 5 th groups, AgNPs to 6th and 7th groups, while CMC-AgNPs were given to 8th and 9th groups. However, indomethacin
$(10 \mathrm{mg} / \mathrm{kg})$ was given as standard to the 10th group of animals.

\section{Cotton Pellet Induced Granuloma in Rats}

After administration of 1 st dose to all ten groups, the aseptic cotton pellet of approximately $10 \mathrm{mg}$ was implanted subcutaneously in the back of the anesthetized rats and administered each test solution once daily for 7 days. After one week of administration, each animal was euthanized, and cotton pellets were removed and oven-dried at $65{ }^{\circ} \mathrm{C}$. Then, the dried pellets were weighed, and the weight gained after implantation was calculated. ${ }^{51}$ The percent inhibition (PI) in the formation of granuloma was calculated using the following formula:

$$
\mathrm{PI}=\frac{\begin{array}{l}
\text { Cotton pellet weight } \\
\text { in control group }
\end{array}-\begin{array}{l}
\text { Cotton pellet weight } \\
\text { in treated group }
\end{array}}{\text { Cotton pellet weight in control group }} \times 100
$$

\section{Carrageenan Induced Edema in the Rat Paw}

Inflammation was induced in both treated and control group rats by administering the $0.1 \mathrm{~mL}$ carrageenan $(1 \%)$ in the left hind paw after the first dose administration. Rat paw edema was measured multiple times with a $1 \mathrm{~h}$ interval using a plethysmometer. The actual volume of rat paw edema was determined by subtracting the initial reading with subsequent readings. ${ }^{52}$ The percent inhibition (PI) of rat paw edema formation was calculated using the following formula:

$$
\begin{aligned}
& \mathrm{PI}=\frac{\begin{array}{l}
\text { Mean edema volume } \\
\text { in control group }
\end{array}}{\text { Mean edema volume in control group }} \begin{array}{l}
\text { Mean edema volume } \\
\text { in treated group }
\end{array} \\
& \times 100
\end{aligned}
$$

\section{Determination of Inflammatory Biomarkers \\ Determination of Leukocyte Counts, C-Reactive Protein (CRP), and Cytokines Levels}

Before the administration of acetic acid with a concentration of $0.05 \mathrm{~N}$ via intraperitoneal route, test solutions were given to the above defined ten groups of rats. Then, peritoneal exudate was drawn, and the total number of leukocytes and CRP levels were measured after $3 \mathrm{~h}$ administration of acetic acid. ${ }^{53}$ However, different cytokines including interleukins (IL)-1, IL-2, IL-6, IL10 , and tumor necrosis factor-alpha (TNF- $\alpha$ ) were 
estimated using MAGPIX (R\&D Systems) according to the instructions provided by manufacturer's on commercial assay kits. ${ }^{54}$

\section{Cyclooxygenase-I and Cyclooxygenase-2 Assay}

The inhibitory potential of SAEE, CMC, AgNPs, and CMC-AgNPs on COX-1 and COX-2 was evaluated according to the method reported by $\mathrm{Li}$ et al in $2003 .{ }^{55}$ Initially, both enzymes were activated by placing each enzyme on ice with a cofactor solution containing L-epinephrine, hematin, and reduced glutathione in the Tris-Hcl buffer for $5 \mathrm{~min}$. Then, test solutions with the concentrations of SAEE (125 and $250 \mu \mathrm{g} / \mathrm{mL}) ; \mathrm{CMC}$, AgNPs, and CMC-AgNPs (2.5 and $5 \mu \mathrm{g} / \mathrm{mL})$ and indomethacin $(100 \mu \mathrm{g} / \mathrm{mL})$ were added to each enzyme solution. Then, the reaction was started by adding arachidonic acid as an activator. These samples were incubated for 10-15 min at $37{ }^{\circ} \mathrm{C}$; then, formic acid (4.0 M) was added for terminating the reaction process. The levels of arachidonic acid metabolites, which were synthesized due to this reaction indicated the activity of COX-1 and COX2 enzymes. Finally, these metabolites were further separated, and their levels were measured by a liquid scintillation counter.

\section{5-Lipoxygenase and 12-Lipoxygenase Assay}

Test samples with the same concentrations used for COXs assay were treated with 5-lipoxygenase (46 $\mu \mathrm{g}$ protein) and 12-lipoxygenase (18 $\mu \mathrm{g}$ protein) individually for $10-15 \mathrm{~min}$ at $24{ }^{\circ} \mathrm{C}$ before starting the enzymatic reaction with arachidonic acid. Then, formic acid was added with a concentration of $4.0 \mathrm{M}$ for acidifying the reaction. 5-HETE and 12-HETE metabolites were synthesized due to the reactions of 5-LO and 12-LO, respectively, and their levels indicated the activity of these enzymes. The levels of these metabolites were determined using a liquid scintillation counter. $^{55}$

\section{Anti-Leishmaniasis Activity}

The anti-leishmaniasis potential of SAEE, CMC, AgNPs, and CMC-AgNPs were evaluated against the culture of Leishmania (L.) major strain (HHK/LL/ 2018/L130), which was received from the pathological laboratory of Hamdard University Hospital-Karachi after cultivation in blood agar. A volume of $3 \mathrm{~mL}$ culture medium containing Fetal Bovine Serum (FBS, $10 \%$ ) was added in different assay tubes with $1 \times 10^{6}$ parasites/mL of L. major. Determination of leishmanicidal potential and $\mathrm{IC}_{50}$ values of each test agent were performed in a dose-dependent manner with the concentrations of $\operatorname{SAEE}(50,100,1000$, and $10,000 \mu \mathrm{g} / \mathrm{mL})$, CMC, AgNPs, and CMC-AgNPs (1, 25, 50, and $100 \mu \mathrm{g} /$ $\mathrm{mL}$ ), while dimethyl sulfoxide (DMSO) and fluconazole were used as control and standard, respectively, in different concentrations. After exposure to each test solution, each tube was incubated at $27^{\circ} \mathrm{C}$. Parasites of L. major strain were counted by (Model QJ-1102, Qiujing, China) after $24 \mathrm{~h}$ incubation period, and the activity of each test solution was expressed as percent viability of parasites at different concentrations. $^{56}$

\section{Antioxidant Activity}

The 2,2-diphenyl-1-picrylhydrazyl (DPPH) radical scavenging activity was assessed using the previously described method by Ahn et al in 2019. ${ }^{57}$ Each test and standard (butylated hydroxyl toluene) solution was used in the concentration range of 1 to $500 \mu \mathrm{g} / \mathrm{mL}$ for the evaluation of an antioxidant activity. A volume of $30 \mu \mathrm{L}$ test solution was mixed with an ethanolic solution of DPPH radicals. Before the incubation at $37{ }^{\circ} \mathrm{C}$ for $30 \mathrm{~min}$, plates were wrapped with aluminum foil. Then, the multi-detection reader was used to measure the absorbance at $517 \mathrm{~nm}$. The DPPH radical scavenging potential was evaluated in triplicates.

\section{Cell Line Toxicity Evaluation}

The cytotoxic activity of synthesized nanocomposite was assessed using HeLa cell line (ATCC, Virginia, USA), while the (3 (4,5-dimethyl thiazolyl-2) 2.5-diphenyltetrazolium bromide) assay was used for the determination of percentage cell viability. The standard doxorubicin (50 $\mathrm{mg}$ ) was used as a reference drug. The medium containing AgNPs and CMC-AgNPs with concentrations of $25-500 \mu \mathrm{g} / \mathrm{mL}$ were added separately in replacement of adherent culture medium and incubated at room temperature for $24 \mathrm{~h}$. Then, the cells were washed multiple times using phosphate-buffered saline (PBS) and again incubated for $30 \mathrm{~min}$ in MTT reagent (1 $\mathrm{mg} / \mathrm{mL})$. After incubation, percentage cell viability 
and proliferative potential were determined using contrast microscopy and UV spectrophotometry techniques at $570 \mathrm{~nm}^{58}$ Each test solution was evaluated in triplicates.

The inhibition in cell growth was calculated in percentages with the help of the following formula:

$$
\begin{aligned}
\text { Cell inhibition }(\%)= & \left.\left(100-\left[A_{t}-A_{b}\right),\left(A_{c} A_{b}\right)\right]\right) \\
& \times 100
\end{aligned}
$$

Whereas,

$A_{t}$ is the absorbance of the test solution, the absorbance of blank is denoted as $A_{b}$ while $A_{c}$ is used for the absorbance of control solution.

\section{Statistical Analysis}

All descriptive findings of this study are given as their mean \pm S.D values. However, inferential analyses were performed using SPSS software (version 23). Analysis of variance (one-way ANOVA) along with Tukey post hoc test was applied for evaluating the significant differences in antibacterial, anti-inflammatory, and anti-leishmaniasis activities among different test solutions. $\mathrm{P}<0.05$ and $\mathrm{P}<0.005$ were considered as statistically significant and highly statistically significant results, respectively. In addition, the correlation coefficient and regression analysis were used to determine the nature of correlations among different test solutions in bacterial time-killing kinetics assay and antioxidant activity.

\section{Results and Discussion}

\section{Synthesis and Characterization of CMC- AgNPs Nanocomposite}

The stable nanocomposite of CMC-AgNPs was successfully synthesized after the reduction of silver ions, and it was confirmed by a UV-Vis spectrophotometer at $406 \mathrm{~nm}$ wavelength (Figure 1). UV-vis spectrum of CMC-AgNPs represents multiple Surface Plasmon Resonance (SPR) bands at different wavelengths indicative of the polymer mixture of CMC along with AgNPs and plant extract. Strong SPR was obtained in the region of $400-420 \mathrm{~nm}$ in both AgNPs and CMC-AgNPs spectrums corresponding to the presence of $\mathrm{Ag}$ ions. ${ }^{45} \mathrm{Li}$ et al and Hassabo et al also reported SPR bands at closer wavelengths ie, $404 \mathrm{~nm}$ and $413 \mathrm{~nm}$, respectively, in spectrums of CMC-based

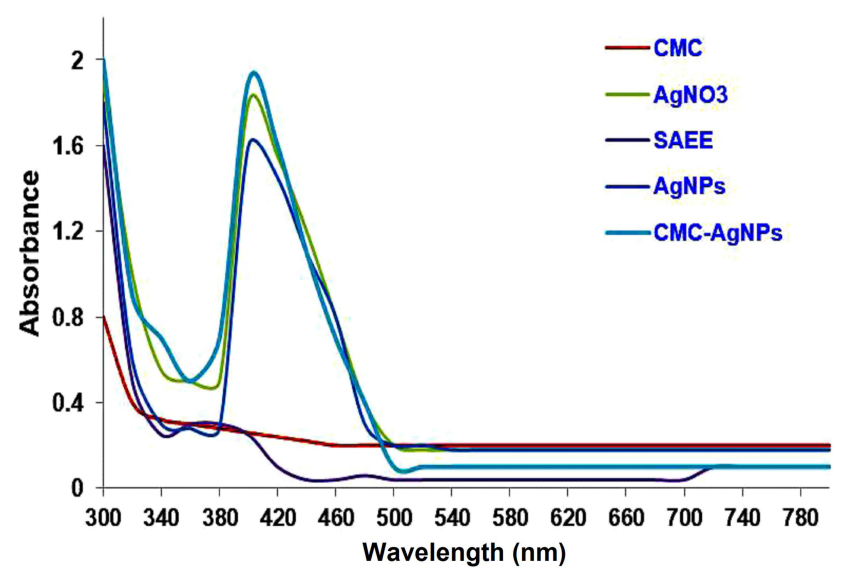

Figure I UV/visible spectra's of carboxymethyl cellulose, $\mathrm{AgNO}_{3}$, Syzygium aromaticum ethanolic extract (SAEE), AgNPs and CMC-AgNPs.

AgNPs. ${ }^{59,60}$ The facial appearance, surface morphology, and internal structure of the synthesized CMCAgNPs were demonstrated by scanning and transmission electron microscopy. Agglomeration and spherical shape AgNPs were observed in SEM images. However, the polymer conjugated silver-based nanocomposites were different in their surface morphology ie, quasispherical. In SEM and TEM images, more agglomeration and rough surfaces were observed in CMCAgExNPs nanocomposites with the size ranges of $30-70 \mathrm{~nm}$ as reflected in Figure 2. This size variation of NPs might be observed due to the agglomeration of CMC with synthesized AgExNPs surfaces. The structural and intermediate configurations of biopolymer can also alter the morphological and biological properties of polymeric NPs. For instance, brush-like or needleshaped molecules reduced the complement activation and phagocytosis, whereas spherical surface favored phagocytosis and also potent complement activators. ${ }^{61}$

The crystallographic morphology of synthesized nanocomposite was determined using the XRD technique as shown in Figure 3. Similar to TEM findings, the low crystalline nature or more agglomeration was observed in CMC-AgNPs in comparison to AgNPs since the more sharp peaks are shown in Figure 3A compared to Figure 3B. ${ }^{62}$ The diffraction angles observed at $10.98^{\circ}(142)$ and $20.53^{\circ}$ (191) refer to the CMC fabrication in the CMC-AgNPs XRD pattern. ${ }^{31}$ However, some Bragg reflections are found in 


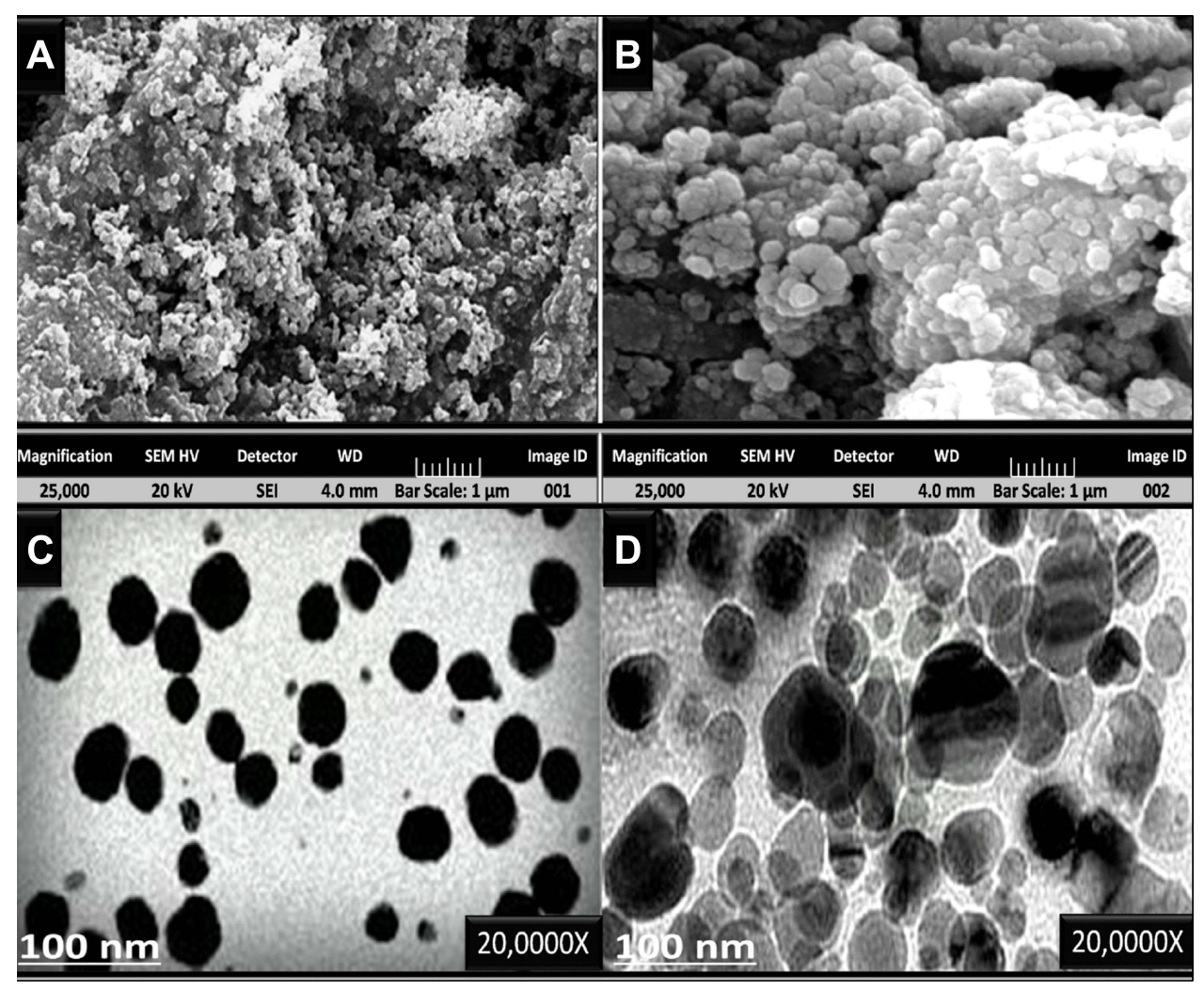

Figure 2 Scanning electron microscopy (SEM) images of (A) AgNPs and (B) CMC-AgNPs and transmission electron images (TEM) images of (C) AgNPs and (D) CMCAgNPs.

Figure 3B with $2 \theta$ of $37.73^{\circ}, 43.92^{\circ}, 64.09^{\circ}, 77.20^{\circ}$, $81.11^{\circ}$, and $97.93^{\circ}$, which correspond to the characteristic face-centered CMC-AgNPs with count indexes (737), (309), (207), (195), (95) and (62), respectively. These peaks broadening are indicating the presence of various size ranges of nanoparticles, which are also reflected in TEM images. The findings of the XRD analysis are in agreement with previous studies, which reported a strong reflection at $33^{\circ}$ and $40^{\circ}$ of the AgNPs. ${ }^{63,64}$ The average crystallite size of CMCAgNPs was found to be about $28 \mathrm{~nm}$ using Scherrer's formula, which is well consistent with the average particle diameter obtained from TEM images.

In the FTIR spectrum, a broad absorption peak observed at $3412 / \mathrm{cm}$, indicating the presence of hydroxyl groups found in clove extract, while the peaks were observed at 476/cm in both AgNPs and CMC-AgNPs spectrums correspond to the presence of $\mathrm{Ag}^{+}$ions ${ }^{14,43}$ (Figure 4). However, in the CMC-AgNPs spectrum, the appearance of some additional peaks and changes in the intensity of spectrum peaks, which were found in the AgNPs spectrum suggested the functional group's interaction between $\mathrm{CMC}$ and $\mathrm{Ag}^{+}$ions. At $2922 / \mathrm{cm}$, $1647 / \mathrm{cm}$, and $1382 / \mathrm{cm}$, absorption peaks reflect the stretching vibration of $\mathrm{C}-\mathrm{H}, \mathrm{C}-\mathrm{O}$, and $\mathrm{C}-\mathrm{O}-\mathrm{H}$ bonds from hydrocarbon chains, respectively. ${ }^{45}$ In EDX spectroscopy, the absorption peak at $3 \mathrm{keV}$ indicated the presence of $\mathrm{Ag}^{+}$ions in the synthesized CMC-AgNPs, with an atomic percentage of $15.58 \% .{ }^{65}$ In addition, the existence of carbon atom signals (32.94\%) in CMCAgNPs indicated the functionalization of CMC with AgNPs as indicated in Figure 5. The particle mean size and their size distribution are the most fundamental physical characteristics of NPs. They directly influence the biological fate, in vivo distribution, targeting ability and toxicity of these types of drug delivery systems. In addition, particle size can also be affected by the degradation rate of different polymeric NPs. It has also been reported that the faster polymeric degradation rate is generally associated with larger size 

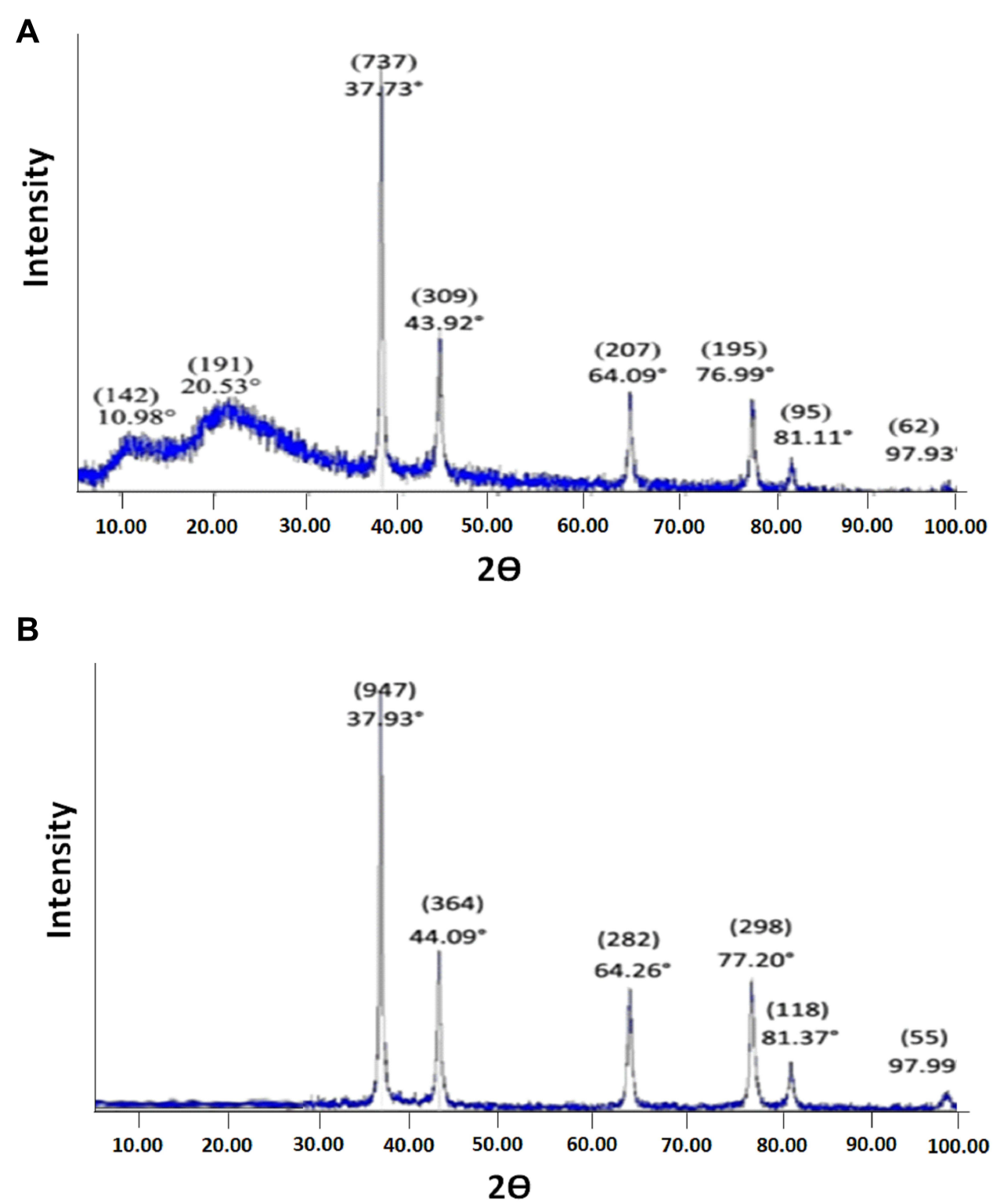

Figure 3 X-ray diffractograms of (A) AgNPs and (B) CMC-AgNPs interpreted with JCPDS reference no 01-087-0597.

polymeric NPs. The size distributions of CMC-AgNPs nanocomposite using the DLS technique are presented in Figure 6. Monodispersion of CMC-AgNPs was observed with the mean size range of $20-30 \mathrm{~nm}$, which is slightly greater than the size of AgNPs, ie $10-20 \mathrm{~nm}$. This increase in size after the functionalization of CMC might be due to the aggregation and nonspecific binding between CMC and AgNPs. Similar monodispersion with nearer particle size range was observed by $\mathrm{Li}$ et al in CMC containing AgNPs. ${ }^{59}$ Figure 7 shows the typical pore size distribution of synthesized nanocomposite. From the graph, we can observe that most of the micropores of CMC-AgNPs with a size smaller than $50 \mathrm{~nm}$, the mean pore size from the peak position is about $18.2 \mathrm{~nm}$, and possesses a relatively narrow pore size distribution. Therefore, these particles are grain clusters, that is, small polycrystals. Moreover, the stability of the synthesized nanocomposite was determined by measuring the mean zeta potential of CMC-AgNPs. It is reported that NPs with the zeta potential range from $-25 \mathrm{mV}$ to $+25 \mathrm{mV}$ have a high degree of stability. ${ }^{66} \mathrm{In}$ 
A

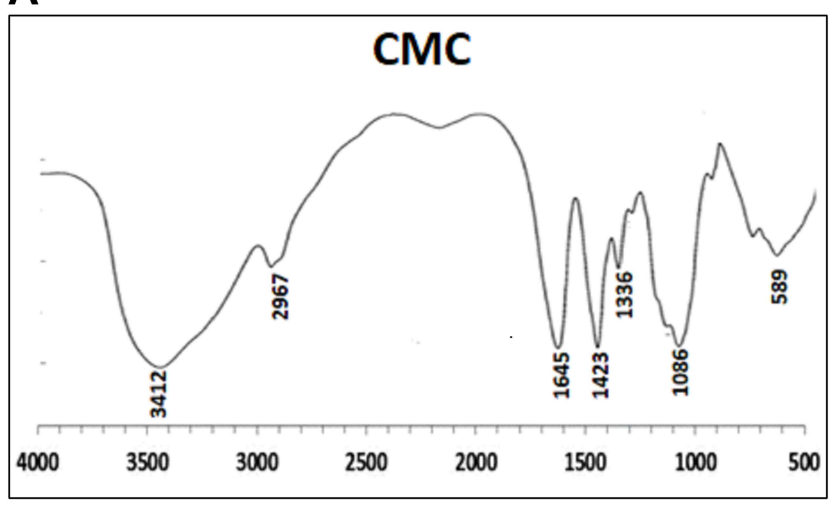

B

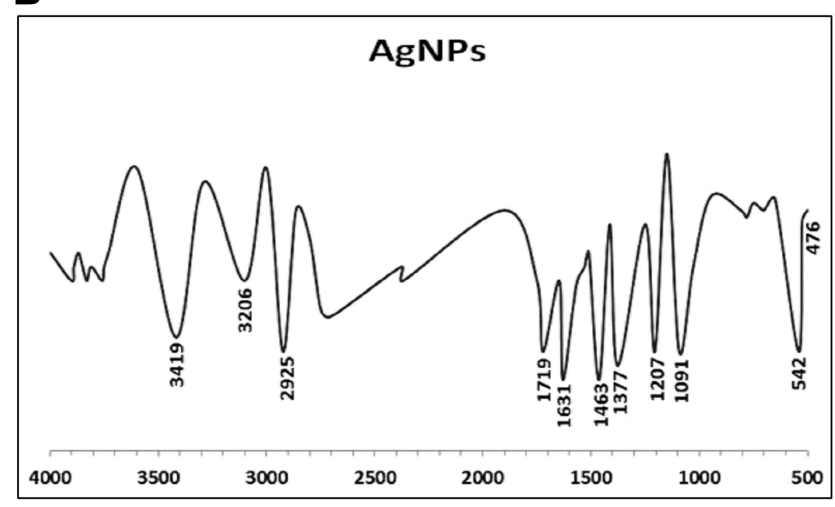

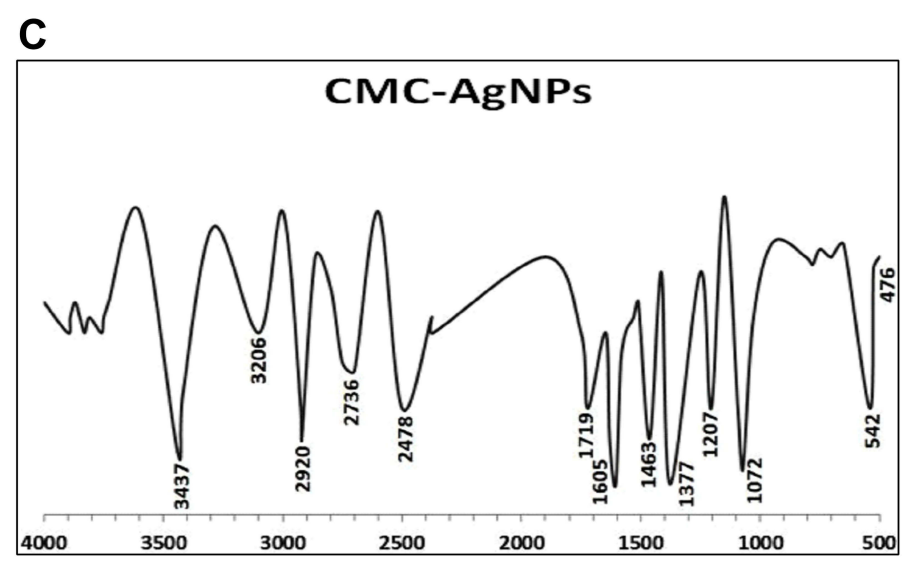

Figure 4 Fourier transforms infrared (FTIR) spectra of (A) CMC, (B) AgNPs and (C) CMC-AgNPs.
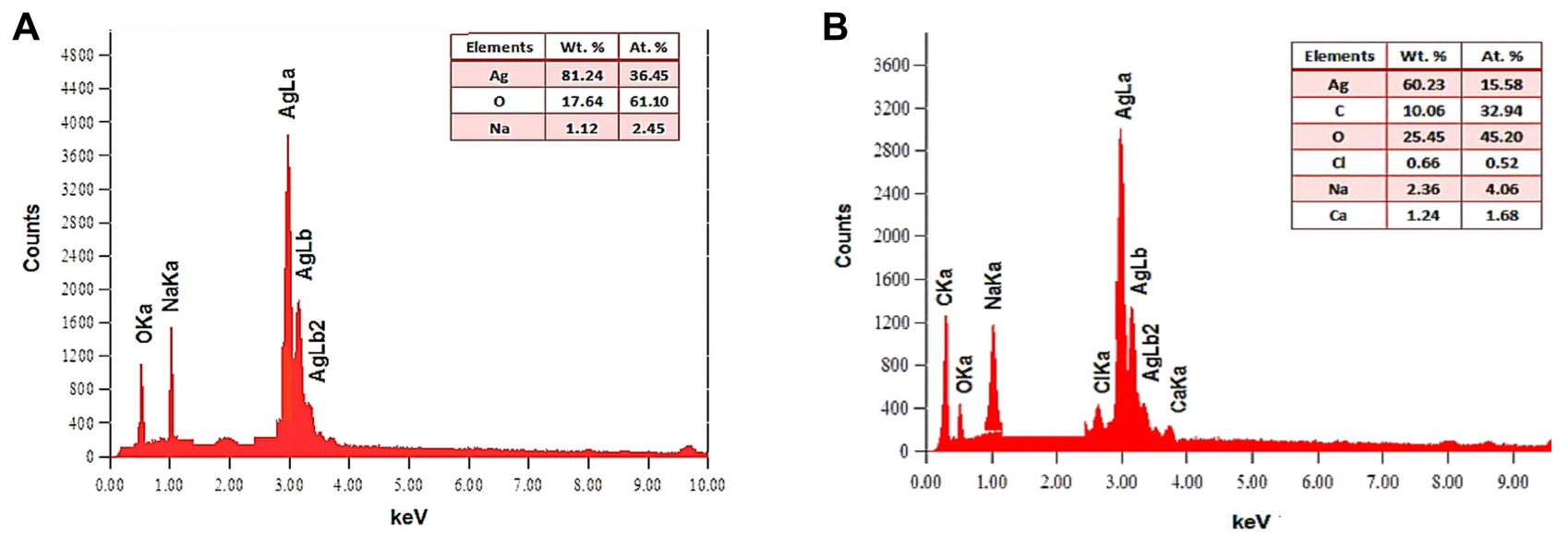

Figure 5 Energy-dispersive X-ray (EDX) spectra's of (A) AgNPs and (B) CMC-AgNPs.

Figure 8, the mean zeta potentials of AgNPs and CMCAgNPs were found to be $-23.6 \mathrm{mV}$ and $-31.6 \mathrm{mV}$, respectively, indicating the stability of synthesized nanocomposite. The shifting of charges towards further negativity after functionalization with $\mathrm{CMC}$ supports high dispersity, good colloidal nature, and long-term stability of synthesized nanocomposite. ${ }^{67}$ However, the variability or negativity in the distribution of 


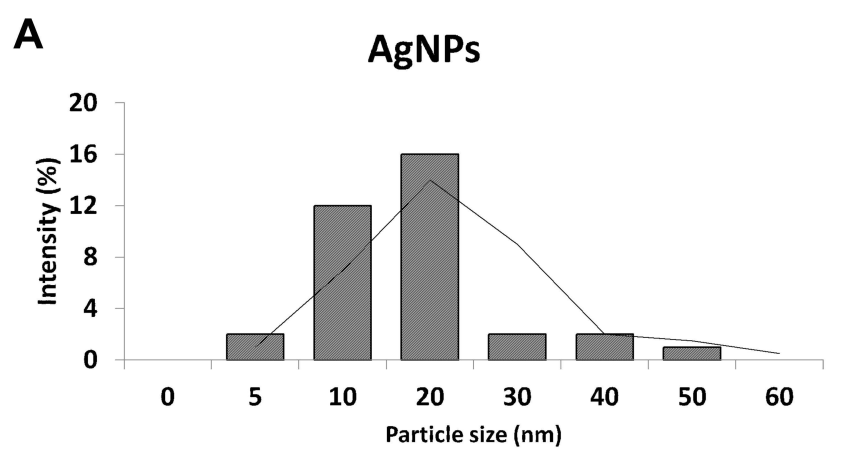

B

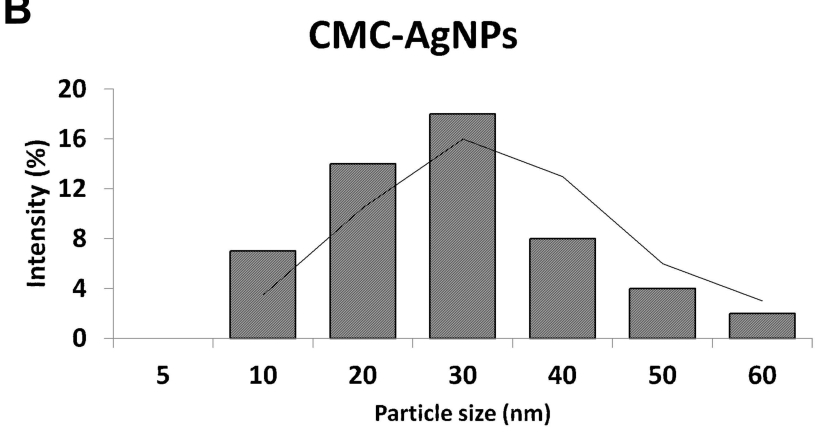

Figure 6 Particle size distribution of (A) AgNPs and (B) CMC-AgNPs. All experiments were performed in triplicates and reported as mean.

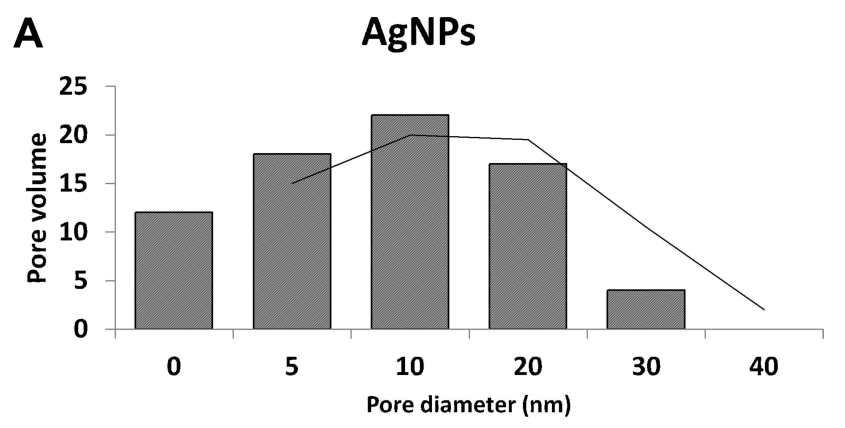

\section{B}

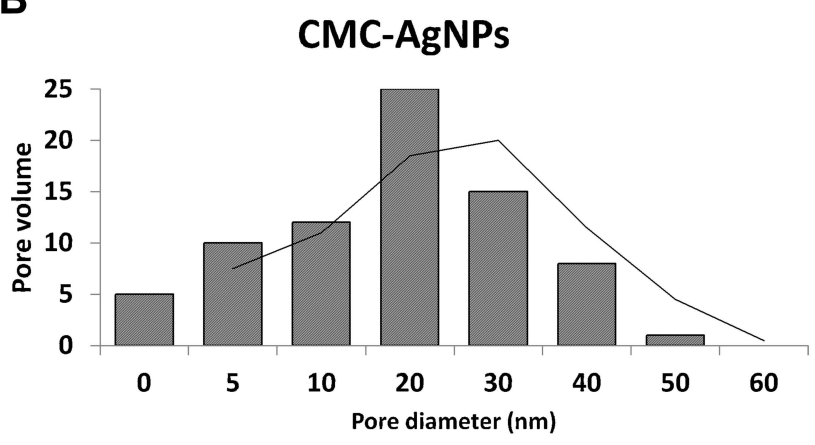

Figure 7 Pore diameter distribution of (A) AgNPs and (B) CMC-AgNPs. All experiments were performed in triplicates and reported as mean. surface charges might be due to the variation in functional groups in both SAEE and polymer structure which indicated the conjugation of natural polymer on the surface of AgNPs. More negative charged functional groups were found in CMC resulted in the shifting of charges towards more negativity after conjugation with CMC. The final yields of obtained nanocomposite of CMC-AgNPs were found to be $41.3 \%$ with the DS of CMC was 0.52 .

\section{Antibacterial Activity}

Pathogenic bacteria have become global threats to public health. The evolution of pathogenic bacteria with resistance to conventional antibiotics has resulted in an urgent need for the development of new and more effective antimicrobial agents. The antibacterial activity of synthesized nanocomposite was evaluated against both Gram-positive and Gram-negative bacterial strains using the Oxford cup diffusion method. The zones of inhibitions found against each isolate are given in Table 1 and also shown in Figure 9. The results demonstrated that the synthesized nanocomposite exhibits highly significant $(P<0.005)$ antibacterial activity compared to control and reference antibiotics against all of the bacterial strains. Amongst all bacterial strains, CMC-AgNPs produced maximum antibacterial activity against $P$. aeruginosa and $K$. pneumonia with the ZIs of $27.9 \pm 0.91 \mathrm{~mm}$ and $27.8 \pm 0.60 \mathrm{~mm}$, respectively.

In addition, CMC-AgNPs inhibited the growth of $S$. epidermidis/K. pneumoniae/P. aeruginosa and S. aureus/S. mutans $/ S$. typhi at $32 \mu \mathrm{g} / \mathrm{mL}$ and $64 \mu \mathrm{g} / \mathrm{mL}$, respectively, while killed similar bacterial strains at $64 \mu \mathrm{g} / \mathrm{mL}$ and 128 $\mu \mathrm{g} / \mathrm{mL}$ concentrations, respectively, which were lowest amongst all tested antibacterial agents as shown in Table 2. Similar augmented antibacterial activity of CMC based AgNPs was also reported in previous studies. ${ }^{59,60}$ The exact mechanism for growth inhibition of bacterial strains by AgNPs is still not identified, while several researchers have reported the plausible bacterial killing mechanism by AgNPs. It has been suggested that the high affinity of AgNPs with the surface-active groups of bacterial strains has produced more significant bactericidal effects. ${ }^{68}$ It is also reported that the bactericidal activity of AgNPs can be produced by rupturing the bacterial cell wall and distortion in the helical structure of bacterial 


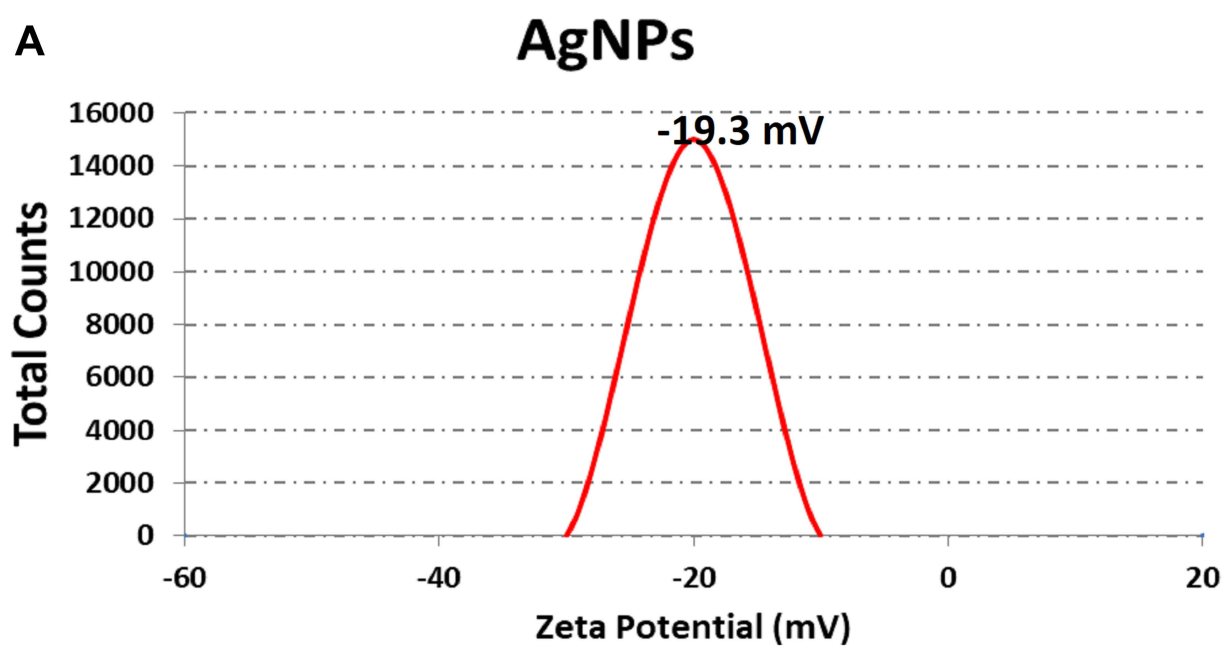

B

\section{CMC-AgNPs}

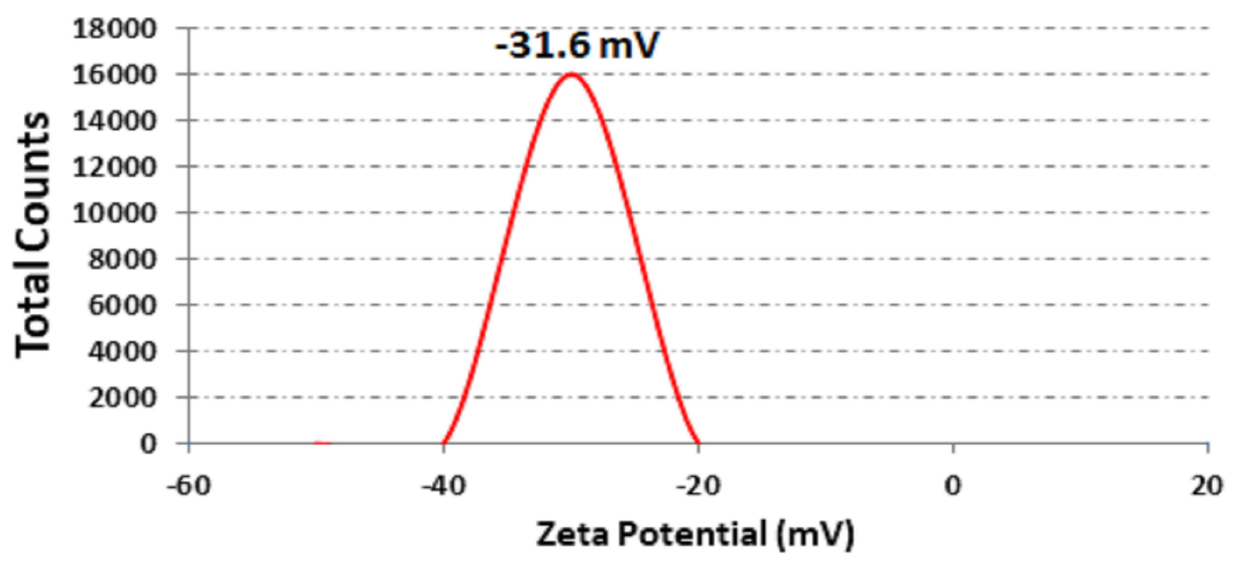

Figure 8 Zeta potential of (A) AgNPs and (B) CMC-AgNPs using DLS technique. All experiments were performed in triplicates and reported as mean.

DNA by $\mathrm{Ag}$ ions. $^{69,70}$ In addition, green synthesized AgNPs reported their antibacterial potential by inhibiting bacterial biofilm. ${ }^{71}$ In the present study, the greater antibacterial activity of CMC-AgNPs was found due to the synergism of antibacterial potential of AgNPs and CMC after combination. This augmented antibacterial activity found might be on account of the Ag-O coordination bonds among AgNPs and $\mathrm{COO}^{-}$moieties of $\mathrm{CMC}$, increasing the ability of AgNPs to release $\mathrm{Ag}^{+}$ions into the aqueous dispersion. ${ }^{59}$ In the same way as AgNPs, the exact mechanism for slight antibacterial activity of $\mathrm{CMC}$ has not been reported in previous studies. However, similar to chitosan, it is suggested that CMC might react with both the bacterial cell wall and the cell membrane, since it also have hydroxyl groups of the glucopyranose monomers. $^{72,73}$

After exposure to the CMC-AgNPs at MBC for $2 \mathrm{~h}$, the growth profiles of each tested bacterial strain at different time intervals are presented in Figure 10. The synthesized nanocomposite of CMC-AgNPs remarkably produced a more drop in viable cells of Gram-negative bacterial strains compared to Gram-positive within $20 \mathrm{~min}$. However, all tested bacterial strains showed a stationary growth phase after $2 \mathrm{~h}$ exposure with CMC-AgNPs. Furthermore, the result of the correlation coefficient test indicated the linear relationship $\left(\mathrm{R}^{2}=0.680\right)$ among viable cell counts of different bacterial strains at different time intervals, while regression analysis showed that the viable 
Table I Zone of Inhibitions (Zls) of Different Antibacterial Agents Against Different Standard Isolates

\begin{tabular}{|c|c|c|c|c|c|c|}
\hline \multirow[t]{2}{*}{ Antimicrobial Agents } & \multicolumn{6}{|c|}{ Zone of Inhibition $(\mathrm{mm} \pm$ S.D) } \\
\hline & S. aureus & S. mutans & S. epidermidis & K. pneumonia & S. typhi & P. aeruginosa \\
\hline Control & $0.00 \pm 0.00$ & $0.00 \pm 0.00$ & $0.00 \pm 0.00$ & $0.00 \pm 0.00$ & $0.00 \pm 0.00$ & $0.00 \pm 0.00$ \\
\hline SAEE & $5.8 \pm 0.32$ & $9.2 \pm 0.25$ & $7.6 \pm 0.41$ & $6.2 \pm 0.34$ & $4.2 \pm 0.22$ & $6.8 \pm 0.31$ \\
\hline CMC & $8.4 \pm 0.45$ & $8.5 \pm 0.71$ & $9.2 \pm 0.53$ & $7.9 \pm 0.54$ & $9.4 \pm 0.51$ & $7.1 \pm 0.25$ \\
\hline $\mathrm{AgNPs}$ & $16.4 \pm 0.48^{*}$ & $11.3 \pm 0.53$ & $18.4 \pm 0.87^{*}$ & $19.5 \pm 0.78^{*}$ & $18.5 \pm 0.45^{*}$ & $15.8 \pm 0.63 *$ \\
\hline CMC-AgNPs & $26.8 \pm 0.72 * *$ & $24.6 \pm 0.85^{* *}$ & $26.3 \pm 0.75^{* *}$ & $27.8 \pm 0.60 * *$ & $25.3 \pm 0.3 I^{* *}$ & $27.9 \pm 0.91 * *$ \\
\hline Amoxicillin & $15.7 \pm 0.22 *$ & $16.3 \pm 0.35^{*}$ & $14.5 \pm 0.13^{*}$ & - & - & - \\
\hline Cefoxitin & - & - & - & $|6.4 \pm 0.2|^{*}$ & $15.2 \pm 0.15^{*}$ & $12.3 \pm 0.25$ \\
\hline
\end{tabular}

Notes: All experiments were performed in triplicates and reported as mean \pm SD. $* p \leq 0.05$ significant as compared to control, $* * p \leq 0.005$ highly significant as compared to control.

Abbreviations: S.D, standard deviation; SAEE, Syzygium aromaticum ethanolic extract; CMC, carboxymethyl cellulose.

cell counts of all bacterial strains significantly $\left(\mathrm{R}^{2}=\right.$ -0.876) decrease with increasing exposure time of CMCAgNPs.

The present study demonstrated that both Grampositive and Gram-negative bacterial strains showed significant sensitivity to green synthesized CMCAgNPs. Therefore, an AFM study was performed on both Gram positive ( $S$. aureus) and Gram negative ( $K$. pneumonia) strains in order to examine the bacterial killing mechanism of the synthesized nanocomposite. The bacterial cells were magnified and captured in rainbow mode to observe the shape, surface and biofilm around bacterial cells. Under the AFM study of bacterial cells (Figure 11), morphological changes in CMC-AgNPs treated bacterial cells were observed in both bacterial strains. AFM images revealed that cells of $S$. aureus and K. pneumonia faced significant cytological and morphological alterations after exposure with CMC-AgNPs. It may be suggested that synthesized nanocomposite has a significant binding affinity with the lipopolysaccharide present on the bacterial cell membrane. This interaction of CMC-AgNPs with lipopolysaccharide altered the morphology of the bacterial cell membrane.

\section{Anti-Inflammatory Activity}

No significant changes were observed in the overall health of all control and test group animals, such as average body weight, physical activity, skin ulceration, salivation, and behavior at initial and during the study period.
Cotton pellet-induced granuloma is a commonly reported method for the evaluation of late phase (chronic) anti-inflammatory activity of testing drugs. ${ }^{74}$ The anti-inflammatory activities produced by SAEE, $\mathrm{CMC}, \mathrm{AgNPs}$, and CMC-AgNPs against cotton pellet induced granuloma formation in rats at different doses are given in Table 3. The synthesized nanocomposite of CMC-AgNPs showed highly significant $(P<0.005)$ antiinflammatory activity with the percent inhibitions of $43.13 \%$ and $48.68 \%$ at the doses of 0.025 and 0.05 $\mathrm{mg} / \mathrm{kg}$, respectively compared to control. However, at same doses of AgNPs $(0.025$ and $0.05 \mathrm{mg} / \mathrm{kg})$, significant $(P<0.05)$ inhibition was observed ie $32.26 \%$ and $36.53 \%$, respectively. The comparable results with CMC-AgNPs were produced by standard drug indomethacin at $10 \mathrm{mg} / \mathrm{kg}$ with the percent inhibitions of $54.42 \%$. Similar dose-dependent anti-inflammatory activity was reported by David et al and Govindappa et al on AgNPs synthesized by Sambucus nigra and Calophyllum tomentosum, respectively. ${ }^{75,76}$ However, no previous data are available for the anti-inflammatory activity of CMC based AgNPs.

Carrageenan-induced acute inflammation is supposed to be the most suitable test for the evaluation of anti-inflammatory activity, and it is associated with cyclooxygenase inhibitors, which are involved in prostaglandin inhibition. ${ }^{77}$ In this inflammatory model, edema is developed in a biphasic curve and inflammation occurs initially in $1 \mathrm{st} \mathrm{h}$ due to the release of inflammatory mediators, ie serotonins and histamines, while edema was mediated with the release of prostaglandins after three hours in 2 nd phase. ${ }^{78}$ It was 


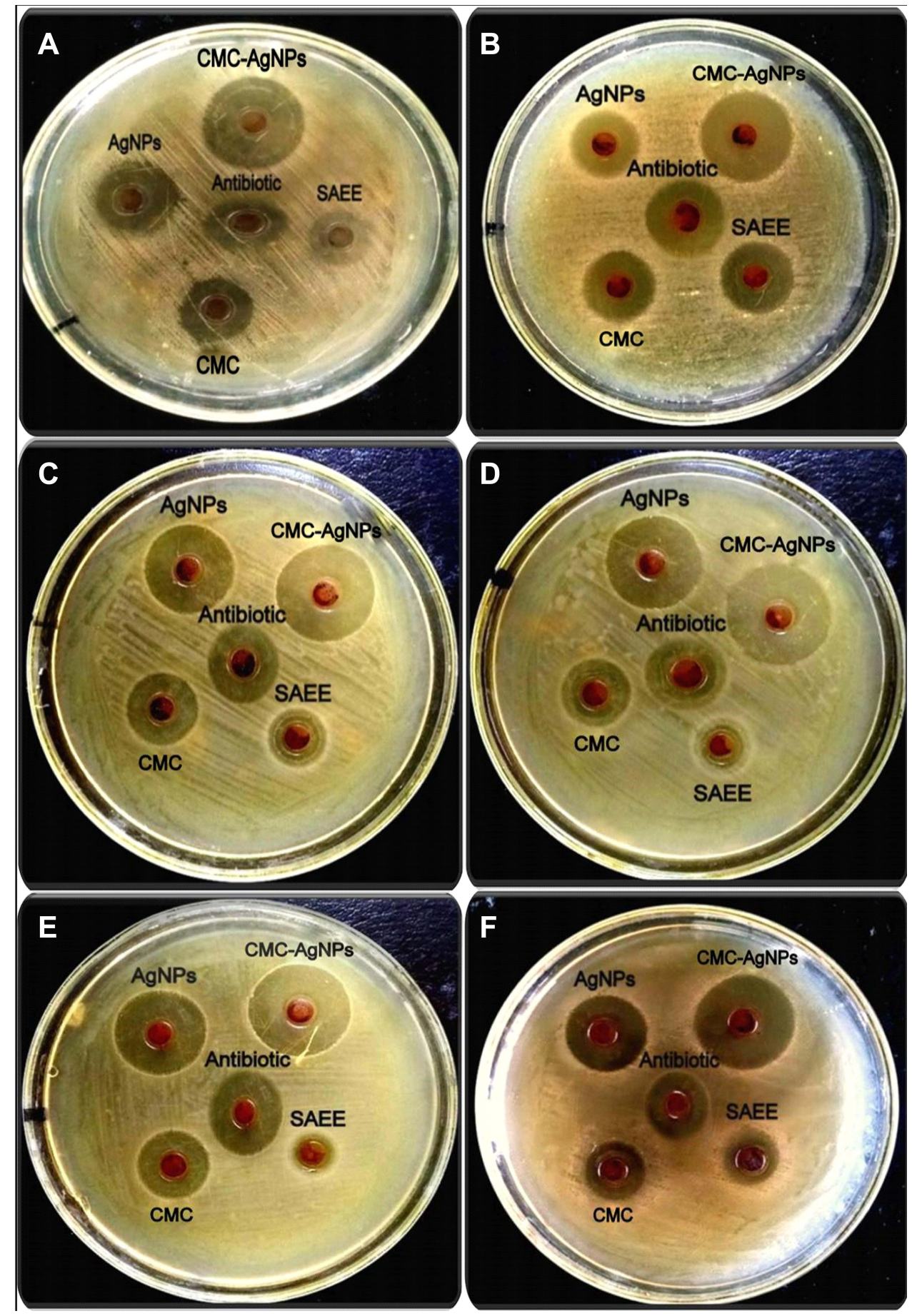

Figure 9 Antibacterial activities of different antimicrobial agents against (A) Staphylococcus aureus, (B) Streptococcus mutans, (C) Staphylococcus epidermidis, (D) Klebsiella pneumonia, (E) Salmonella typhi and (F) Pseudomonas aeruginosa.

seen (Table 4) that there was no significant reduction in rat paw edema in early hours, while significant $(P<0.05)$ and highly significant $(P<0.005)$ reduction in rat paw edema was observed in the second phase of inflammation, which was after $3 \mathrm{~h}$ administration of AgNPs $(0.025 \mathrm{mg} / \mathrm{kg} ; 32.60 \% ; 0.05 \mathrm{mg} / \mathrm{kg}$, $38.04 \%)$ and CMC-AgNPs (0.025 mg/kg; 42.39\%; 0.05 $\mathrm{mg} / \mathrm{kg}, 47.82 \%)$, respectively, in a dose-dependent 
Table 2 Minimum Inhibitory Concentrations (MICs) and Minimum Bactericidal Concentrations (MBCs) of Different Antibacterial Agents Against Different Standard Isolates

\begin{tabular}{|c|c|c|c|c|c|c|c|c|}
\hline \multirow[t]{3}{*}{ Isolates } & \multicolumn{8}{|c|}{ Antimicrobial Agents } \\
\hline & \multicolumn{2}{|c|}{ SAEE } & \multicolumn{2}{|c|}{ CMC } & \multicolumn{2}{|c|}{ AgNPs } & \multicolumn{2}{|c|}{ CMC-AgNPs } \\
\hline & MIC & MBC & MIC & MBC & MIC & MBC & MIC & MBC \\
\hline S. aureus & $7500 \pm 301.3$ & $8500 \pm 526.2$ & $512 \pm 56.5$ & $512 \pm 83.2$ & $128 \pm 12.2$ & $256 \pm 61.6$ & $64 \pm 14.1$ & $128 \pm 12.6$ \\
\hline S. mutans & $5500 \pm 265.2$ & $7500 \pm 415.2$ & $512 \pm 62.1$ & $512 \pm 71.5$ & $256 \pm 24.3$ & $256 \pm 21.9$ & $64 \pm 13.5$ & $128 \pm 31.2$ \\
\hline S. epidermidis & $7500 \pm 323.5$ & $8500 \pm 613.4$ & $256 \pm 34.1$ & $512 \pm 97.4$ & $128 \pm 16.8$ & $256 \pm 52.4$ & $32 \pm 7.7$ & $64 \pm 18.2$ \\
\hline K. pneumonia & $7500 \pm 376.3$ & $7500 \pm 552.9$ & $512 \pm 54.4$ & $512 \pm 52.8$ & $128 \pm 16.7$ & $128 \pm 26.9$ & $32 \pm 8.6$ & $64 \pm 15.0$ \\
\hline S. typhi & $8500 \pm 521.7$ & $9500 \pm 492.4$ & $256 \pm 42.4$ & $512 \pm 82.5$ & $128 \pm 14.0$ & $128 \pm 32.6$ & $64 \pm 14.1$ & $128 \pm 42.9$ \\
\hline P. aeruginosa & $7500 \pm 427.1$ & $8500 \pm 761.0$ & $512 \pm 62.1$ & $512 \pm 102.4$ & $128 \pm 21.3$ & $256 \pm 67.1$ & $32 \pm 6.9$ & $64 \pm 11.3$ \\
\hline
\end{tabular}

Note: All experiments were performed in triplicates and reported as mean \pm SD.

Abbreviations: SAEE, Syzygium aromaticum ethanolic extract; CMC, carboxymethyl cellulose; MIC, minimum inhibitory concentrations; MBC, minimum bactericidal concentrations.

manner. It reflected that the synthesized nanocomposites reduced rat paw edema in a late phase of the inflammatory response, which may be due to the inhibition of the cyclooxygenase pathway, which in turn causes inhibition of prostaglandins. ${ }^{79}$ Hebeish et al also observed a similar late-phase reduction in edema after administration of chemically synthesized AgNPs. ${ }^{80}$

It has been reported that acute inflammation results in the release of different inflammatory mediators and cytokines in peritoneal fluids such as leukocytes, CRP, COX-1, COX-2, 5-LO, 12-LO, IL-1, IL-2, IL-6, and TNF $-\alpha{ }^{81}$ These chemical mediators help in the

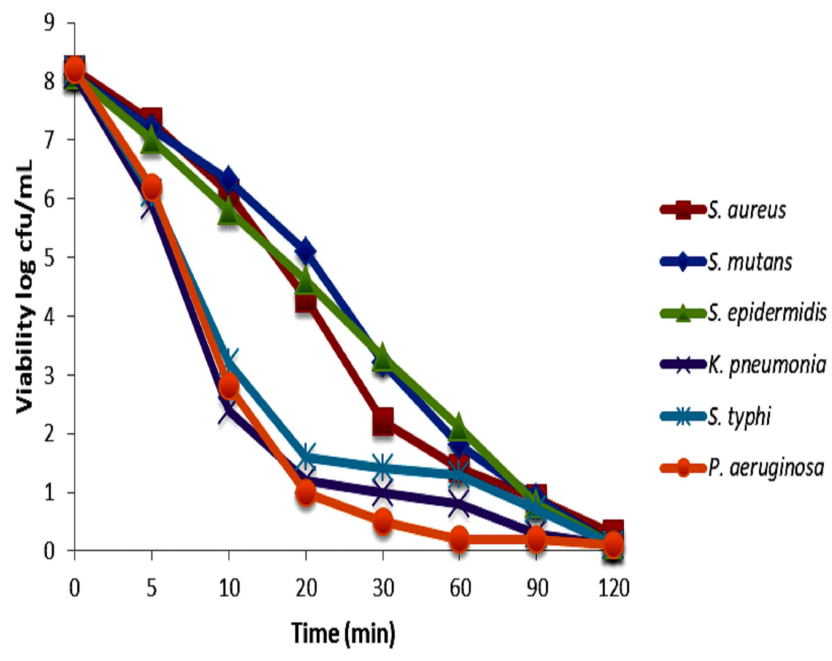

Figure 10 Time killing kinetics of green synthesized CMC-AgNPs nanocomposite against different bacterial isolates. All experiments were performed in triplicates. Linear relationship $\left(R^{2}=0.680\right)$ among viable cells counts of different bacterial strains at different time intervals while the viable cells counts of all bacterial strains significantly $\left(R^{2}=-0.876\right)$ decreases with increasing exposure time of CMC-AgNPs. activation of peripheral chemical mediated inflammatory responses. ${ }^{82}$ In the present study, at the dose of $0.05 \mathrm{mg} /$ $\mathrm{kg}, \mathrm{CMC}-\mathrm{AgNPs}$ caused highly significant decrease $(p<0.005)$ in leukocyte count $(922 \pm 83)$ levels of CRP $(8.4 \pm 0.73 \mathrm{mg} / \mathrm{mL})$, IL-1 $(177.4 \pm 21.3 \mathrm{pg} / \mathrm{mL})$, IL-2 $(83.7 \pm 11.5 \mathrm{pg} / \mathrm{mL})$, IL-6 $(83.7 \pm 11.5 \mathrm{pg} / \mathrm{mL})$ and TNF- $\alpha \quad(18.3 \pm 5.3 \mathrm{pg} / \mathrm{mL})$ compared to control (Table 5). Moreover, Figure 12 shows the significant $(p<0.05)$ and highly significant $(p<0.005)$ reduction in cyclooxygenase and lipoxygenase enzymes at the concentrations of $2.5 \mu \mathrm{g} / \mathrm{mL}$ and $5 \mu \mathrm{g} / \mathrm{mL}$ CMC-AgNPs, respectively. All these findings indicated the potent antiinflammatory potential of CMC-AgNPs and were also in agreement with previous studies reporting the antiinflammatory activity of AgNPs alone. ${ }^{80,83,84}$

\section{Anti-Leishmaniasis Activity}

The leishmanicidal activity of SAEE, CMC, and synthesized nanocomposites of AgNPs and CMC-AgNPs were tested for $24 \mathrm{~h}$ against $L$. major strain and the results are expressed as percentage cell viability of parasite at different concentrations (Table 6). The number of viable parasites was counted in both control and treated groups at different concentrations. At a concentration of $50 \mu \mathrm{g} / \mathrm{mL}, A g N P s$ and CMC-AgNPs exhibited significant $(P<0.05)$ and highly significant $(P<0.005)$ antileishmaniasis activity, with the viable parasite count being decreased up to $61.5 \%$ and $36.7 \%$, respectively in comparison with the control group. Moreover, a 50\% reduction in viable parasite count was observed within $24 \mathrm{~h}$ exposure with AgNPs and CMC-AgNPs with the $\mathrm{IC}_{50}$ values of $94.13 \mu \mathrm{g} / \mathrm{mL}$ and $28.41 \mu \mathrm{g} / \mathrm{mL}$, 
A

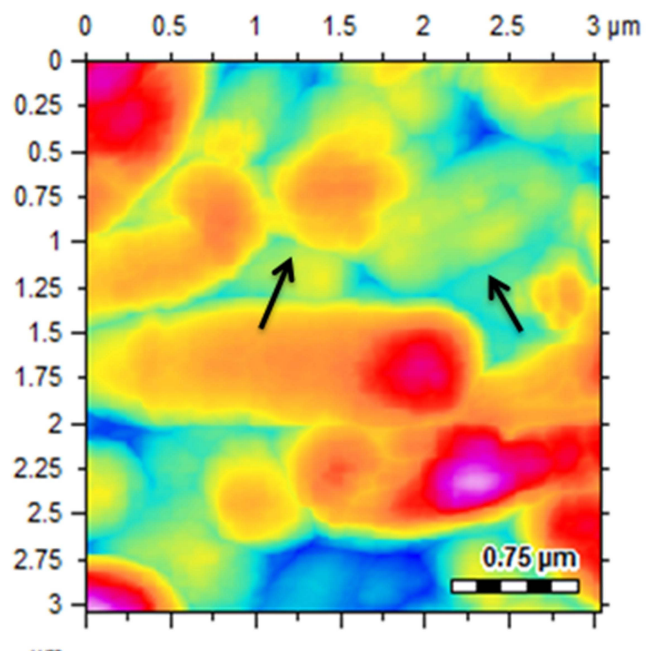

$\mu \mathrm{m}$
B
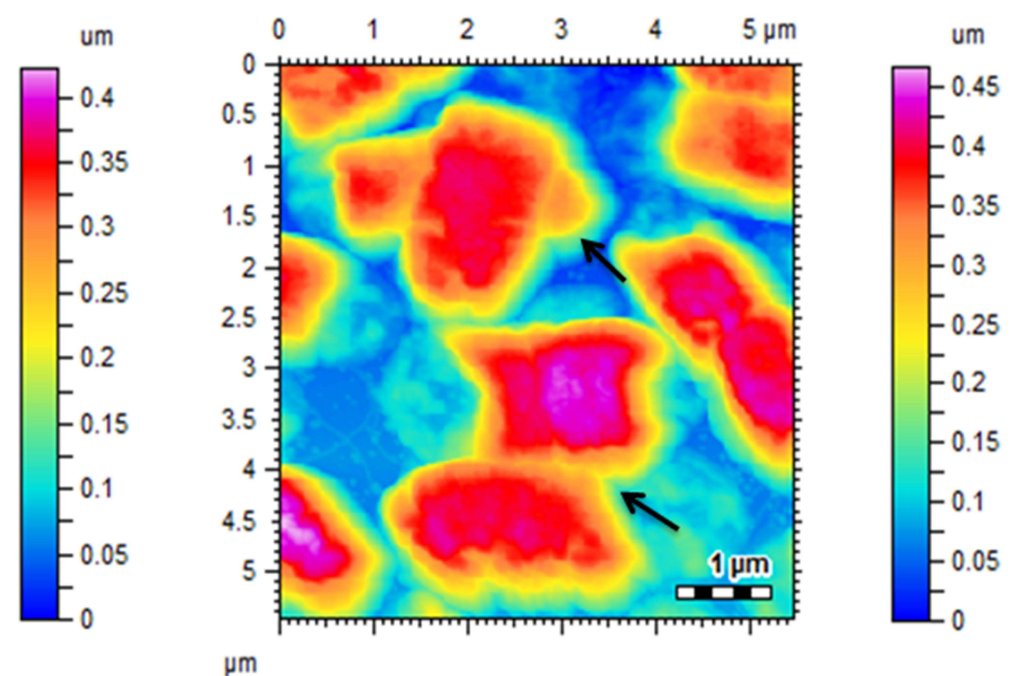

Figure II Atomic force microscopic (AFM) images of (A) S. aureus and (B) K. pneumonia after treated with CMC-AgNPs. Arrows show significant damage in bacterial cell membrane while few bacteria were completely lysed.

respectively. Jebali et al and Allahverdiyev et al reported comparable in-vitro anti-leishmaniasis activity of chemically synthesized AgNPs against L. major and L. tropica strains, respectively. ${ }^{85,86}$ It has been observed that any drug that could produce reactive oxygen species (ROS) would be highly susceptible to Leishmania strains due to its highly sensitive nature towards these ROS. $^{87}$ However, several studies already reported that metal NPs produce ROS that destroys microorganisms through oxidative damage. ${ }^{88-90}$ Thus, the use of AgNPs as an anti-leishmanial agent might act as a large reservoir of silver ions, which would provide ROS and would destroy the invaded parasites, while the mechanism for increasing leishmanicidal potential of AgNPs after conjugation with $\mathrm{CMC}$ should be further investigated.

\section{Antioxidant Activity}

The production of free radicals induces cell impairment, which is seriously harmful to humans and

Table 3 Anti-Inflammatory Activity of Different Test Solutions Against Cotton Pellet Induced Granuloma in Rats

\begin{tabular}{|c|c|c|c|c|c|}
\hline Groups & $\begin{array}{l}\text { Doses } \\
\text { (mg/kg) }\end{array}$ & $\begin{array}{c}\text { Weight of Moist Cotton } \\
\text { Pellet }(\mathbf{m g})\end{array}$ & $\begin{array}{c}\text { Weight of Dried Cotton } \\
\text { Pellet }(\mathrm{mg})\end{array}$ & $\begin{array}{l}\text { Weight of Granuloma } \\
\text { (mg) }\end{array}$ & $\begin{array}{c}\text { Inhibition } \\
\text { (\%) }\end{array}$ \\
\hline Control & - & $214.70 \pm 6.21$ & $49.42 \pm 5.77$ & 165.28 & - \\
\hline SAEE & $\begin{array}{l}125 \\
250\end{array}$ & $\begin{array}{l}152.57 \pm 4.87 \\
145.32 \pm 5.30\end{array}$ & $\begin{array}{l}30.54 \pm 3.11 \\
28.41 \pm 3.58\end{array}$ & $\begin{array}{l}122.03 \\
116.9 \mid\end{array}$ & $\begin{array}{l}26.16 \\
29.26\end{array}$ \\
\hline CMC & $\begin{array}{c}0.025 \\
0.05\end{array}$ & $\begin{array}{l}|55.87 \pm 8.2| \\
|5| .22 \pm 6.59\end{array}$ & $\begin{array}{l}31.45 \pm 4.58 \\
29.97 \pm 6.88\end{array}$ & $\begin{array}{l}124.42 \\
121.25\end{array}$ & $\begin{array}{l}24.72 \\
26.63\end{array}$ \\
\hline AgNPs & $\begin{array}{c}0.025 \\
0.05\end{array}$ & $\begin{array}{l}|42.50 \pm 5.2| \\
\mid 37.58 \pm 5.98\end{array}$ & $\begin{array}{l}30.54 \pm 3.09 \\
32.68 \pm 4.20\end{array}$ & $\begin{array}{l}111.96 * \\
104.9 *\end{array}$ & $\begin{array}{l}32.26 \\
36.53\end{array}$ \\
\hline CMC-AgNPs & $\begin{array}{c}0.025 \\
0.05\end{array}$ & $\begin{array}{l}\mid 18.54 \pm 4.67 \\
106.35 \pm 4.21\end{array}$ & $\begin{array}{l}24.56 \pm 3.19 \\
21.54 \pm 3.64\end{array}$ & $\begin{array}{l}93.98 * * \\
84.81 * *\end{array}$ & $\begin{array}{l}43.13 \\
48.68\end{array}$ \\
\hline Indomethacin & 10 & $95.87 \pm 2.50$ & $20.54 \pm 2.01$ & $75.33 * *$ & 54.42 \\
\hline
\end{tabular}

Notes: $n=10$, average values \pm S.D. $* p \leq 0.05$ significant as compared to control; **p $\leq 0.005$ highly significant as compared to control. $n=10$, average values \pm S.D. Abbreviations: SAEE, Syzygium aromaticum ethanolic extract; CMC, carboxymethyl cellulose. 
Table 4 Anti-Inflammatory Activity of Different Test Solutions Against Carrageenan-Induced Edema in the Rat Paw

\begin{tabular}{|l|c|c|c|c|c|}
\hline Groups & Doses (mg/kg) & $\mathbf{I ~ h}$ & $\mathbf{3} \mathbf{h}$ & $\mathbf{6} \mathbf{h}$ & \% Inhibition at 6 h \\
\hline Control & - & $0.44 \pm 0.04$ & $0.89 \pm 0.03$ & $0.92 \pm 0.02$ & - \\
\hline SAEE & 125 & $0.41 \pm 0.02$ & $0.82 \pm 0.02$ & $0.72 \pm 0.02$ & 21.73 \\
& 250 & $0.38 \pm 0.03$ & $0.76 \pm 0.02$ & $0.66 \pm 0.04$ & 28.26 \\
\hline CMC & 0.025 & $0.42 \pm 0.04$ & $0.84 \pm 0.02$ & $0.76 \pm 0.03$ & 17.39 \\
& 0.05 & $0.40 \pm 0.03$ & $0.79 \pm 0.02$ & $0.69 \pm 0.05$ & 25.00 \\
\hline AgNPs & 0.025 & $0.39 \pm 0.02$ & $0.77 \pm 0.03$ & $0.62 \pm 0.05^{*}$ & 32.60 \\
& 0.05 & $0.38 \pm 0.02$ & $0.69 \pm 0.03$ & $0.57 \pm 0.03^{*}$ & 38.04 \\
\hline CMC-AgNPs & 0.025 & $0.38 \pm 0.02$ & $0.70 \pm 0.04$ & $0.53 \pm 0.06 * *$ & 42.39 \\
& 0.05 & $0.37 \pm 0.03$ & $0.57 \pm 0.04$ & $0.48 \pm 0.05^{* *}$ & 47.82 \\
\hline Indomethacin & 10 & $0.39 \pm 0.02$ & $0.48 \pm 0.03 * *$ & $0.42 \pm 0.02^{* *}$ & 54.34 \\
\hline
\end{tabular}

Notes: $n=10$, average values \pm S.D. ${ }^{*} p \leq 0.05$ significant as compared to control; $* * p \leq 0.005$ highly significant as compared to control. Abbreviations: SAEE, Syzygium aromaticum ethanolic extract; CMC, carboxymethyl cellulose.

Table 5 Effect of the Different Anti-Inflammatory Agent on Peritoneal Inflammatory Exudates

\begin{tabular}{|l|c|c|c|c|c|c|c|}
\hline \multirow{2}{*}{ Groups } & \multicolumn{7}{|c|}{ Acetic Acid-Induced Peritoneal Inflammation } \\
\cline { 2 - 8 } & $\begin{array}{c}\text { Doses } \\
(\mathbf{m g} / \mathbf{k g})\end{array}$ & $\begin{array}{c}\text { Leukocytes/mL } \\
\text { of Exudate }\end{array}$ & CRP (mg/mL) & IL-I (pg/mL) & IL-2 (pg/mL) & IL-6 (pg/mL) & TNF- $\alpha$ (pg/mL) \\
\hline Control & - & $2347 \pm 42$ & $18.5 \pm 0.91$ & $302.5 \pm 23.9$ & $214.5 \pm 12.4$ & $815.0 \pm 37.1$ & $108.5 \pm 10.6$ \\
\hline SAEE & 125 & $1922 \pm 45$ & $15.2 \pm 0.55$ & $275.2 \pm 19.5$ & $189.2 \pm 21.8$ & $748.2 \pm 46.5$ & $91.2 \pm 21.5$ \\
& 250 & $1717 \pm 57$ & $13.8 \pm 0.67$ & $260.8 \pm 22.6$ & $168.2 \pm 17.4$ & $613.6 \pm 40.7$ & $77.6 \pm 12.6$ \\
\hline CMC & 0.025 & $2022 \pm 46$ & $16.8 \pm 0.52$ & $288.1 \pm 27.5$ & $201.1 \pm 21.3$ & $786.1 \pm 38.2$ & $96.8 \pm 20.2$ \\
& 0.05 & $1894 \pm 52$ & $14.2 \pm 0.74$ & $276.9 \pm 25.7$ & $186.9 \pm 22.6$ & $714.2 \pm 38.4$ & $83.9 \pm 18.4$ \\
\hline AgNPs & 0.025 & $1621 \pm 59^{*}$ & $12.7 \pm 0.85^{*}$ & $256.7 \pm 20.8^{*}$ & $167.7 \pm 18.3^{*}$ & $601.7 \pm 41.5^{*}$ & $76.0 \pm 12.5^{*}$ \\
& 0.05 & $1401 \pm 63^{*}$ & $11.2 \pm 0.94^{*}$ & $241.2 \pm 17.4^{*}$ & $136.6 \pm 19.7^{*}$ & $461.9 \pm 34.9 *$ & $58.9 \pm 12.4^{*}$ \\
\hline CMC-AgNPs & 0.025 & $1149 \pm 50^{* *}$ & $10.0 \pm 0.8 I^{* *}$ & $211.0 \pm 22.8^{* *}$ & $110.2 \pm 16.3^{* *}$ & $378.8 \pm 27.1^{* *}$ & $35.8 \pm 9.1^{* *}$ \\
& 0.05 & $922 \pm 83^{* *}$ & $8.4 \pm 0.73^{* *}$ & $177.4 \pm 21.3^{* *}$ & $83.7 \pm 11.5^{* *}$ & $189.3 \pm 35.7^{* *}$ & $18.3 \pm 5.3^{* *}$ \\
\hline Indomethacin & 10 & $674 \pm 18^{* *}$ & $7.1 \pm 0.21^{* *}$ & $145.1 \pm 13.2^{* *}$ & $38.6 \pm 2.5^{* *}$ & $97.2 \pm 7.3^{* *}$ & $7.2 \pm 1.1^{* *}$ \\
\hline
\end{tabular}

Notes: $\mathrm{n}=10$, average values \pm SD. $* p \leq 0.05$ significant as compared to control; ** $p \leq 0.005$ highly significant as compared to control.

Abbreviations: CRP, C-reactive protein; IL, interleukins; TNF- $\alpha$, tumor necrotic factors alpha; SAEE, Syzygium aromaticum ethanolic extract; CMC, carboxymethyl cellulose.

animal's health. The reactive oxygen species (ROS) or free radicals have been implicated in the development of cancer, including the initiation, promotion, and progression phases. $^{91}$ ROS may interfere with nuclear signal transduction pathways, cause alterations in DNA structure, and modulate genes related to cell apoptosis. ${ }^{92}$ Antioxidant agents play a pivotal role against these free radicals. ${ }^{93}$ In addition, in certain cases, which are at the threshold of developing diseases like Alzheimer's and diabetes, the human body calls for an external source of antioxidants. ${ }^{94}$ DPPH assay is the most suitable technique used to assess the antioxidant potential of testing drugs. ${ }^{95}$ The DPPH radical scavenging activity of SAEE, CMC, AgNPs, and CMC-AgNPs is presented in Figure 13. The results show that AgNPs and CMC-AgNPs produced potent radical scavenging potential than reference BHT with the $\mathrm{IC}_{50}$ values of $146 \mu \mathrm{g} / \mathrm{mL}$ and 112 


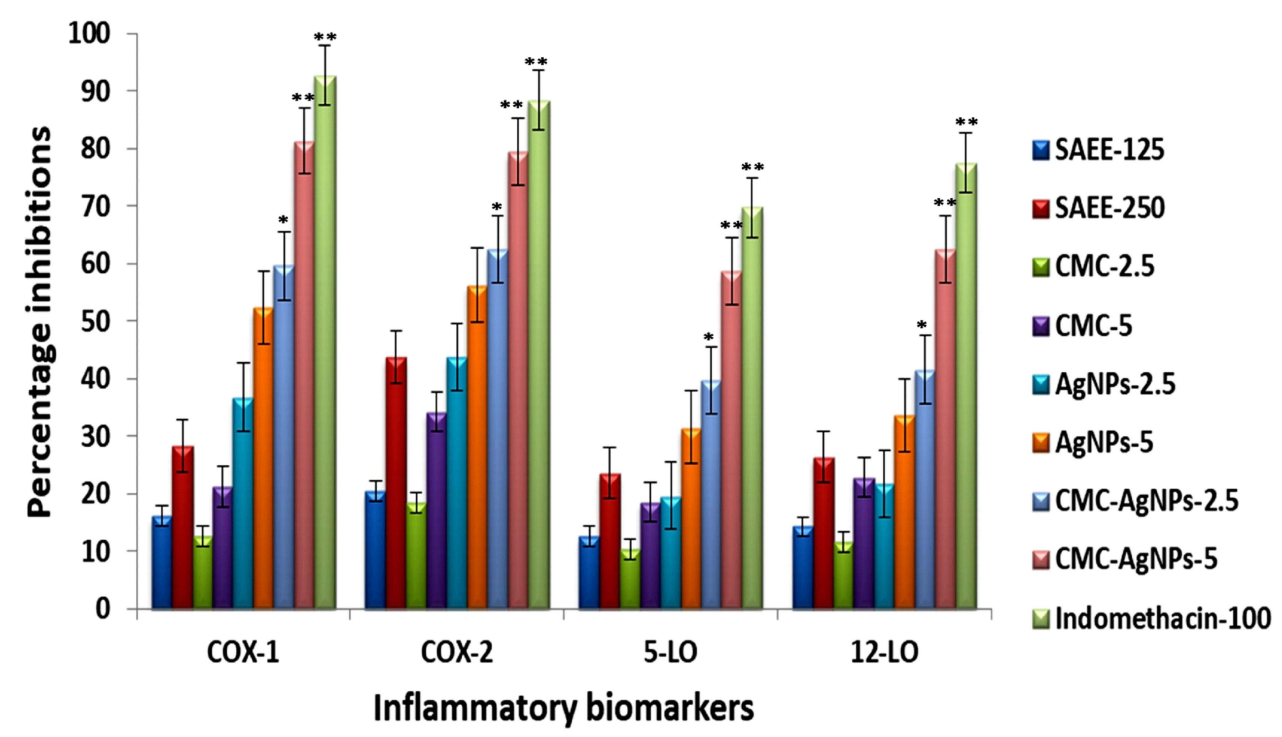

Figure 12 Percentage inhibitions of different inflammatory biomarkers by CMC-AgNPs. Values are given as $\bar{x} \pm \mathrm{S} . \mathrm{D}$ in $\mu g / \mathrm{mL}(\mathrm{n}=6$ ). $* p \leq 0.05$ significant as compared to control, **p $\leq 0.005$ highly significant as compared to control.

Abbreviations: SAEE- I25, Syzygium aromaticum ethanolic extract ( $125 \mu \mathrm{g} / \mathrm{mL})$; SAEE-250, Syzygium aromaticum ethanolic extract $(250 \mu \mathrm{g} / \mathrm{mL})$; $\mathrm{CMC}-2.5$, carboxymethyl

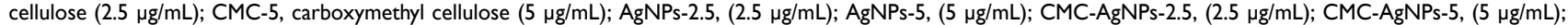
Indomethacin-100, (100 $\mu \mathrm{g} / \mathrm{mL})$.

$\mu \mathrm{g} / \mathrm{mL}$, respectively. Moreover, the percentage radicals were significantly $\left(\mathrm{R}^{2}=0.929\right)$ inhibited with the increasing concentration of each test solution, while very weak correlations $\left(\mathrm{R}^{2}=0.268\right)$ are found among all the test solutions for their antioxidant activity. However, all tested solutions were reduced by more than $50 \%$ of DPPH radicals at different concentrations. This antioxidant activity may be due to the capping constituents present in plant extract and on a metal surface. In addition, it is reported that the phenolic compounds may contribute directly to anti-oxidative action. Zangeneh et al, Al-Shmgani et al, and Chandrasekharan et al reported much comparable antioxidant potential of AgNPs synthesized using Stachys lavandulifolia and Catharanthus roseus and Melia azedarach respectively. ${ }^{96-98}$

\section{Cytotoxic Activity}

Although there are various studies reported on the green synthesis of AgNPs and their coating with different biopolymers, according to our literature review there is no single study available on cytotoxic potentials of CMC fabricated green synthesized AgNPs, particularly in the context of cell apoptosis. In the present study, cytotoxic effects of AgNPs and CMC-AgNPs on HeLa cells line were evaluated using MTT assay, and the results are presented in Figure 14. CMC-AgNPs produced the highest cell viability $(95.4 \%)$ at the dose of $25 \mu \mathrm{g} / \mathrm{mL}$, while a significant and highly significant reduction in percentage living cells ie 57.3\% and $8.1 \%$ were observed at 100 and $250 \mu \mathrm{g} / \mathrm{mL}$ concentrations, respectively, in comparison to control. However, the $\mathrm{LC}_{50}$ of CMC-AgNPs was obtained at $108.2 \mu \mathrm{g} / \mathrm{mL}$, which was significantly higher than the effective concentrations used in the present study for the evaluation of different activities.

In the last, Table 7 shows a brief comparison in the antibacterial, antioxidant and cytotoxic potential of AgNPs, CMC, CMC-AgNPs, chitosan, tragacanth gum, Arabic gum, sodium alginate, and carboxymethyl starch. The findings showed that CMC fabricated AgNPs have the highest antibacterial and antioxidant activities with low cytotoxic potential compared to other tested solutions.

\section{Conclusion}

On the basis of obtained findings, it is concluded that the carboxymethyl cellulose conjugated silver-based nanocomposite can be readily prepared using Syzygium aromaticum ethanolic extract. This is a simple, reliable, green, inexpensive and economical biological procedure that could promote the industrial 
Table 6 Percentage Cell Viability of Leishmania major Strain Against Different Test Solutions at Different Concentrations

\begin{tabular}{|c|c|c|c|}
\hline Groups & Doses $\mu \mathrm{g} / \mathrm{mL}$ & Viability (\%) & $\mathrm{IC}_{50} \mathrm{\mu g} / \mathrm{mL}$ \\
\hline $\begin{array}{l}\text { DMSO } \\
(\mathrm{v} / \mathrm{v})\end{array}$ & $\begin{array}{c}1000 \\
5,000 \\
10,000 \\
25,000\end{array}$ & $\begin{array}{l}100 \\
100 \\
100 \\
100\end{array}$ & - \\
\hline SAEE & $\begin{array}{c}50 \\
100 \\
1000 \\
10,000\end{array}$ & $\begin{array}{c}100 \\
100 \\
94.1 \pm 4.26 \\
75.5 \pm 3.40\end{array}$ & $-^{\alpha}$ \\
\hline CMC & $\begin{array}{c}1 \\
25 \\
50 \\
100\end{array}$ & $\begin{array}{c}100 \\
94.8 \pm 5.41 \\
78.4 \pm 6.05 \\
74.4 \pm 2.49\end{array}$ & $-^{\alpha}$ \\
\hline $\mathrm{AgNPs}$ & $\begin{array}{c}1 \\
25 \\
50 \\
100\end{array}$ & $\begin{array}{c}93.6 \pm 3.32 \\
74.1 \pm 3.12 \\
61.5 \pm 1.87 * \\
48.4 \pm 2.49 *\end{array}$ & 94.13 \\
\hline CMC-AgNPs & $\begin{array}{c}1 \\
25 \\
50 \\
100\end{array}$ & $\begin{array}{c}74.3 \pm 4.72 \\
53.6 \pm 4.13 \\
36.7 \pm 2.54 * * \\
7.2 \pm 1.83 * *\end{array}$ & 28.41 \\
\hline Fluconazole & $\begin{array}{c}1 \\
25 \\
50 \\
100\end{array}$ & $\begin{array}{c}72.2 \pm 3.57 \\
52.5 \pm 0.43 \\
29.4 \pm 0.47 * * \\
4.3 \pm 0.52^{* *}\end{array}$ & 25.17 \\
\hline
\end{tabular}

Notes: $n=6, * p \leq 0.05$ significant as compared to control; **p $\leq 0.005$ highly significant as compared to control. ${ }^{\alpha}$ These agents did not killed viable parasites up to $50 \%$ at any concentration.

Abbreviations: IC, inhibitory concentration; DMSO, dimethyl sulfoxide; SAEE, Syzygium aromaticum ethanolic extract; CMC, carboxymethyl cellulose.

production of CMC-AgNPs without using any harmful reducing, capping and dispersing agent. The

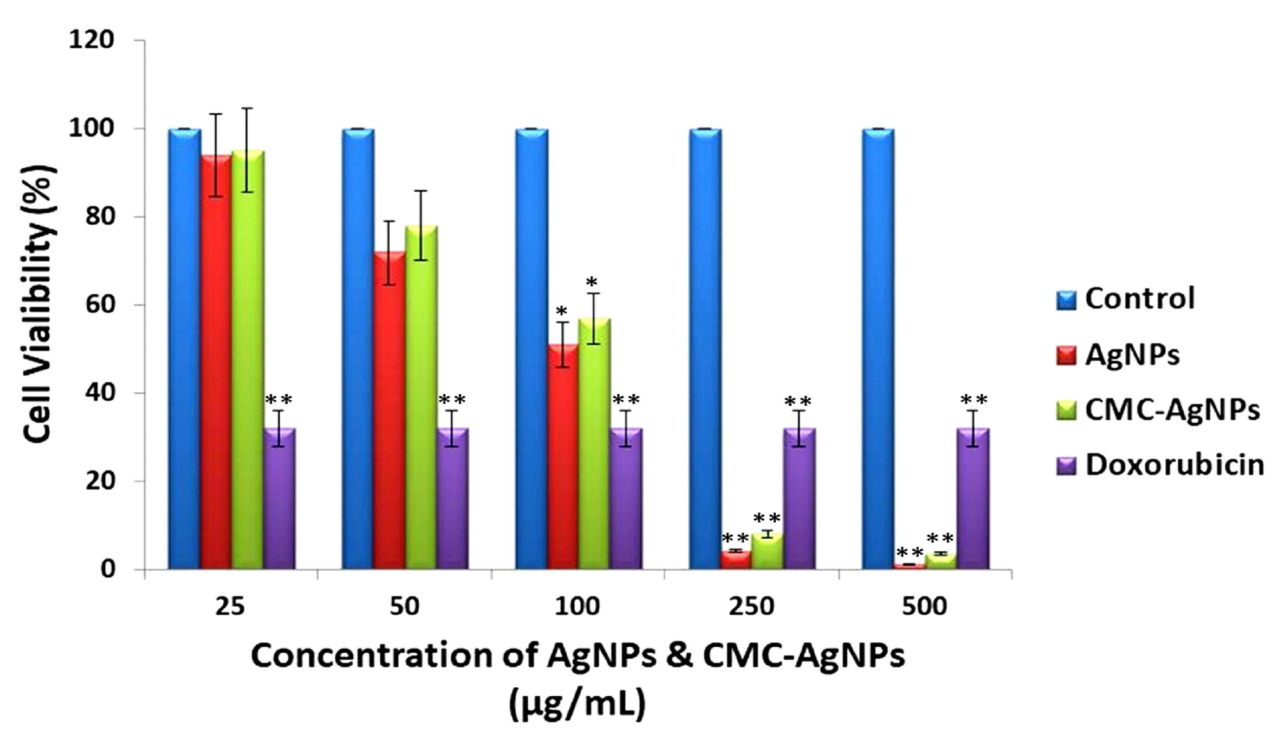

Figure 14 Percentage viability of HeLA cells treated with different concentrations of AgNPs and CMC-AgNPs compared with control and standard doxorubicin at 50 mg standard dose. Data is represented as average values \pm SEM. ${ }^{*} p \leq 0.05$ significant and ${ }^{* *} p \leq 0.005$ highly significant as compared to control.

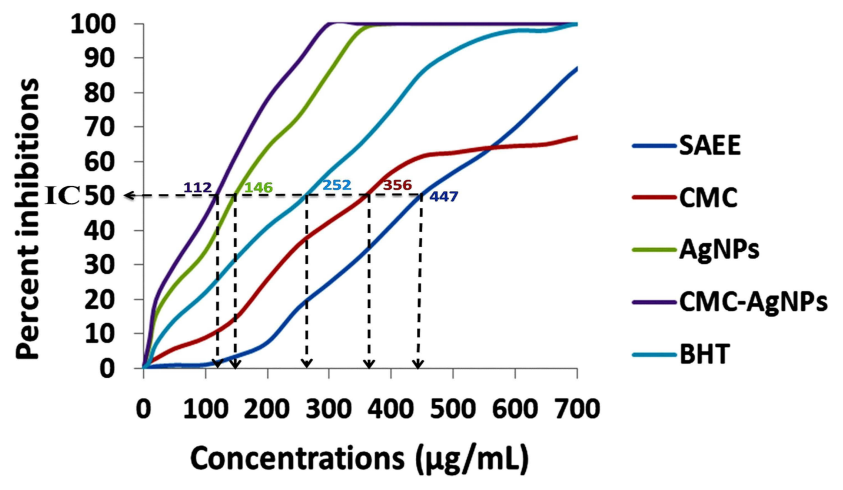

Figure 13 DPPH radical scavenging activities of different test solutions. All experiments were performed in triplicates. DPPH radicals were significantly $\left(R^{2}=0.929\right)$ inhibited with increasing concentration of each test solution while very weak correlations $\left(R^{2}=0.268\right)$ were found among all test solutions.

synthesized nanocomposite appeared to be of uniform size and shape with optimum physical characteristics. CMC-AgNPs possess highly significant antibacterial, anti-inflammatory, anti-leishmaniasis, and antioxidant potential. In addition, synthesized nanocomposite also showed low cytotoxic potential in MTT assay against HeLa cell line compared to AgNPs alone. Therefore, due to the stable nature and potential antibacterial, anti-inflammatory, anti-leishmaniasis, and antioxidant activities, it is suggested that $S$. aromaticum synthesized CMC functionalized AgNPs may be well utilized as a medicinal agent in the biomedical field. In addition, this research can also be further explored for the mechanism of synergistic therapeutic activities of synthesized CMC-AgNPs nanocomposite. 
Table 7 Comparisons in Antibacterial, Antioxidant and Cytotoxic Potential of Different Tested Solutions

\begin{tabular}{|c|c|c|c|}
\hline Test Solutions & $\begin{array}{l}\text { Antibacterial } \\
\text { MIC }(\mu \mathrm{g} / \mathrm{mL})\end{array}$ & $\begin{array}{l}\text { Antioxidant } \\
I_{50}(\mu \mathrm{g} / \mathrm{mL})\end{array}$ & $\begin{array}{l}\text { Cytotoxicity } \\
\text { LC }_{50}(\mu \mathrm{g} / \mathrm{mL})\end{array}$ \\
\hline AgNPs & 128 & 146 & 102.7 \\
\hline CMC & 512 & 356 & —* \\
\hline CMC-AgNPs & 64 & 112 & 108 \\
\hline Chitosan & 256 & 278 & —* \\
\hline Tragacanth gum & 256 & 640 & 一* \\
\hline Arabic gum & 30 & 240 & —* \\
\hline Sodium alginate & 10 & 1.24 & -* \\
\hline $\begin{array}{l}\text { Carboxymethyl } \\
\text { starch }\end{array}$ & 60 & 800 & 一* \\
\hline
\end{tabular}

Note: $*$ These agents did not killed viable parasites up to $50 \%$ at any concentration.

\section{Disclosure}

The authors report no conflicts of interest in this work.

\section{References}

1. Busquets MA, Estelrich J. Prussian blue nanoparticles: synthesis, surface modification, and biomedical applications. Drug Discov Today. 2020;25 (8):1431-1443. doi:10.1016/j.drudis.2020.05.014

2. Wu X, Yang H, Yang W, et al. Nanoparticle-based diagnostic and therapeutic systems for brain tumors. J Mater Chem B. 2019;7 (31):4734-4750.

3. Zare EN, Padil VV, Mokhtari B, et al. Advances in biogenically synthesized shaped metal-and carbon-based nanoarchitectures and their medicinal applications. Adv Colloid Interface Sci. 2020;283:102236.

4. Lee SH, Jun B-H. Silver nanoparticles: synthesis and application for nanomedicine. Int J Mol Sci. 2019;20(4):865.

5. Park SY, Lu G, Kim B, et al. Study on physicochemical, photocatalytic, and biological properties of silver nanoparticles formed using extracts of different parts of Cudrania tricuspidata. Nanomaterials. 2020;10(7):1350.

6. Abdollahi Z, Zare EN, Salimi F, Goudarzi I, Tay FR, Makvandi P. Bioactive carboxymethyl starch-based hydrogels decorated with $\mathrm{CuO}$ nanoparticles: antioxidant and antimicrobial properties and accelerated wound healing in vivo. Int J Mol Sci. 2021;22 (5):2531.

7. Salleh A, Naomi R, Utami ND, et al. The potential of silver nanoparticles for antiviral and antibacterial applications: a mechanism of action. Nanomaterials. 2020;10(8):1566.

8. Sánchez-López E, Gomes D, Esteruelas G, et al. Metal-based nanoparticles as antimicrobial agents: an overview. Nanomaterials. 2020;10(2):292.

9. Makvandi P, Iftekhar S, Pizzetti F, et al. Functionalization of polymers and nanomaterials for water treatment, food packaging, textile and biomedical applications: a review. Environ Chem Lett. 2020;19:1-29.

10. Janani N, Zare EN, Salimi F, Makvandi P. Antibacterial tragacanth gum-based nanocomposite films carrying ascorbic acid antioxidant for bioactive food packaging. Carbohydr Polym. 2020;247:116678. doi:10.1016/j.carbpol.2020.116678

11. Khawaja H, Zahir E, Asghar MA, Asghar MA. Graphene oxide, chitosan and silver nanocomposite as a highly effective antibacterial agent against pathogenic strains. Colloids Surf a Physicochem Eng Asp. 2018;555:246-255. doi:10.1016/j.colsurfa. 2018.06.052
12. Khawaja H, Zahir E, Asghar MA, Asghar MA. Graphene oxide decorated with cellulose and copper nanoparticle as an efficient adsorbent for the removal of malachite green. Int J Biol Macromol. 2021;167:23-34. doi:10.1016/j.ijbiomac.2020.11.137

13. Makvandi P. Wang CY, Zare EN, Borzacchiello A, Niu LN, Tay FR. Metal-based nanomaterials in biomedical applications: Antimicrobial activity and cytotoxicity aspects. Adv Funct Mater. 2020;30:1910021.

14. Asghar MA, Yousuf RI, Shoaib MH, Asghar MA. Antibacterial, anticoagulant and cytotoxic evaluation of biocompatible nanocomposite of chitosan loaded green synthesized bioinspired silver nanoparticles. Int J Biol Macromol. 2020;160:934-943.

15. Guo Y, Yang X, Ruan K, et al. Reduced graphene oxide heterostructured silver nanoparticles significantly enhanced thermal conductivities in hot-pressed electrospun polyimide nanocomposites. ACS Appl Mater Interfaces. 2019;11(28):25465-25473.

16. Gou L, Xiang M, Ni X. Development of wound therapy in nursing care of infants by using injectable gelatin-cellulose composite hydrogel incorporated with silver nanoparticles. Mater Lett. 2020; 277:128340.

17. Gao C, Wang X, Wang H, Zhou J, Zhai S, An Q. Highly efficient and stable catalysis of p-nitrophenol via silver/lignin/polyacrylic acid hydrogel. Int J Biol Macromol. 2020;144:947-953.

18. Sportelli MC, Tütüncü E, Picca RA, et al. Inhibiting P. fluorescens biofilms with fluoropolymer-embedded silver nanoparticles: an insitu spectroscopic study. Sci Rep. 2017;7(1):1-13.

19. Li J, Peng W-J, Fu Z-J, et al. Achieving high electrical conductivity and excellent electromagnetic interference shielding in poly (lactic acid)/silver nanocomposites by constructing large-area silver nanoplates in polymer matrix. Composites Part B. 2019;171:204-213.

20. Haider MS, Shao GN, Imran S, et al. Aminated polyethersulfonesilver nanoparticles (AgNPs-APES) composite membranes with controlled silver ion release for antibacterial and water treatment applications. Mater Sci Eng C. 2016;62:732-745.

21. Palem RR, Rao KM, Kang TJ. Self-healable and dual-functional guar gum-grafted-polyacrylamidoglycolic acid-based hydrogels with nano-silver for wound dressings. Carbohydr Polym. 2019;223: 115074.

22. Karimi-Maleh H, Ranjbari S, Tanhaei B, et al. Novel 1-butyl-3methylimidazolium bromide impregnated chitosan hydrogel beads nanostructure as an efficient nanobio-adsorbent for cationic dye removal: kinetic study. Environ Res. 2021;195:110809.

23. Makvandi P, Ghomi M, Padil VV, et al. Biofabricated nanostructures and their composites in regenerative medicine. ACS Appl Nano Mater. 2020;3(7):6210-6238.

24. Orooji Y, Irani-Nezhad MH, Hassandoost R, Khataee A, Pouran SR, Joo SW. Cerium doped magnetite nanoparticles for highly sensitive detection of metronidazole via chemiluminescence assay. Spectrochim Acta A Mol Biomol Spectrosc. 2020;234:118272.

25. Orooji Y, Ghanbari M, Amiri O, Salavati-Niasari M. Facile fabrication of silver iodide/graphitic carbon nitride nanocomposites by notable photo-catalytic performance through sunlight and antimicrobial activity. J Hazard Mater. 2020;389:122079.

26. Arefi-Oskoui S, Khataee A, Safarpour M, Orooji Y, Vatanpour V. A review on the applications of ultrasonic technology in membrane bioreactors. Ultrason Sonochem. 2019;58:104633.

27. Bilal M, Iqbal H. Marine seaweed polysaccharides-based engineered cues for the modern biomedical sector. Mar Drugs. 2020;18(1):7.

28. Chi K, Catchmark JM. Improved eco-friendly barrier materials based on crystalline nanocellulose/chitosan/carboxymethyl cellulose polyelectrolyte complexes. Food Hydrocoll. 2018;80:195-205.

29. Kanikireddy V, Varaprasad K, Jayaramudu T, Karthikeyan C, Sadiku R. Carboxymethyl cellulose-based materials for infection control and wound healing: a review. Int J Biol Macromol. 2020;164:963-975.

30. Oladapo BI, Oshin EA, Olawumi AM. Nanostructural computation of 4D printing carboxymethylcellulose (CMC) composite. Nano-Struct Nano-Objects. 2020;21:100423. 
31. Prema P, Thangapandiyan S, Immanuel G. CMC stabilized nano silver synthesis, characterization and its antibacterial and synergistic effect with broad spectrum antibiotics. Carbohydr Polym. 2017; 158:141-148.

32. Adnan S, Ranjha NM, Hanif M, Asghar S. O-Carboxymethylated chitosan; A promising tool with in-vivo anti-inflammatory and analgesic properties in albino rats. Int $J$ Biol Macromol. 2020;156:531-536.

33. Akhtar HMS, Riaz A, Hamed YS, et al. Production and characterization of CMC-based antioxidant and antimicrobial films enriched with chickpea hull polysaccharides. Int J Biol Macromol. 2018;118:469477.

34. Govindappa M, Tejashree S, Thanuja V, et al. Pomegranate fruit fleshy pericarp mediated silver nanoparticles possessing antimicrobial, antibiofilm formation, antioxidant, biocompatibility and anticancer activity. J Drug Deliv Sci Technol. 2021;61:102289.

35. Narayanan M, Divya S, Natarajan D, et al. Green synthesis of silver nanoparticles from aqueous extract of Ctenolepis garcini L. and assess their possible biological applications. Process Biochem. 2021;107:91-99.

36. Nandana CN, Christeena M, Bharathi D. Synthesis and characterization of chitosan/silver nanocomposite using rutin for antibacterial, antioxidant and photocatalytic applications. J Cluster Sci. 2021;2:111.

37. Bharathi D, Vasantharaj S, Bhuvaneshwari V. Green synthesis of silver nanoparticles using Cordia dichotoma fruit extract and its enhanced antibacterial, anti-biofilm and photo catalytic activity. Mater Res Express. 2018;5(5):055404.

38. Solomon MM, Gerengi H, Umoren SA. Carboxymethyl cellulose/ silver nanoparticles composite: synthesis, characterization and application as a benign corrosion inhibitor for St37 steel in 15\% $\mathrm{H} 2 \mathrm{SO} 4$ medium. ACS Appl Mater Interfaces. 2017;9(7):6376-6389.

39. Martínez-Rodríguez M, Madla-Cruz E, Urrutia-Baca VH, de la Garza-ramos MA, González-González VA, Garza-Navarro MA. Influence of polysaccharides' molecular structure on the antibacterial activity and cytotoxicity of green synthesized composites based on silver nanoparticles and carboxymethyl-cellulose. Nanomaterials. 2020;10(6): 1164

40. Eyler R, Klug E, Diephuis F. Determination of degree of substitution of sodium carboxymethylcellulose. Anal Chem. 1947;19(1):24-27.

41. Asghar MA, Asghar MA. Green synthesized and characterized copper nanoparticles using various new plants extracts aggravate microbial cell membrane damage after interaction with lipopolysaccharide. Int J Biol Macromol. 2020;160:1168-1176.

42. Asghar MA, Asghar MA, Rehman AA, et al. Synthesis and characterization of graphene oxide nanoparticles and their antimicrobial and adsorption activity against aspergillus and aflatoxins. Latin Am J Pharm. 2019;38(5):1036-1044.

43. Asghar MA, Zahir E, Shahid SM, et al. Iron, copper and silver nanoparticles: green synthesis using green and black tea leaves extracts and evaluation of antibacterial, antifungal and aflatoxin B1 adsorption activity. LWT. 2018;90:98-107.

44. Asghar MA, Yousuf RI, Shoaib MH, et al. Synergistic nanocomposites of different antibiotics coupled with green synthesized chitosanbased silver nanoparticles: characterization, antibacterial, in vivo toxicological and biodistribution studies. Int $J$ Nanomedicine. 2020;15:7841.

45. Asghar MA, Zahir E, Asghar MA, Iqbal J, Rehman AA. Facile, onepot biosynthesis and characterization of iron, copper and silver nanoparticles using Syzygium cumini leaf extract: as an effective antimicrobial and aflatoxin B1 adsorption agents. PLoS One. 2020;15(7): e0234964.

46. Mumtaz N, Asghar MA, Naqvi SBS, Asghar MA, Raza ML, Rehman AA. Time kill assay and bactericidal mechanism of action of ethanolic flowers extract of Sphaeranthus indicus. RADS J Pharm Pharmaceutical Sci. 2019;7(1):27-33.
47. Shafiq Y, Naqvi SBS, Rizwani GH, et al. Assessment of killing kinetics assay and bactericidal mechanism of crude methanolic bark extract of Casuarina equisetifolia. Pak J Pharm Sci. 2018;31 (5):2143-2148.

48. Burki S, Burki ZG, Jahan N, et al. GC-MS profiling, FTIR, metal analysis, antibacterial and anticancer potential of Monotheca buxifolia (Falc.) leaves. Pak J Pharm Sci. 2019;2:32.

49. Rehman AA, Riaz A, Asghar MA, Raza ML, Ahmed S, Khan K. In vivo assessment of anticoagulant and antiplatelet effects of Syzygium cumini leaves extract in rabbits. BMC Complement Altern Med. 2019;19(1):236.

50. Bernard T. Guidelines on the Care and Use of Animals for Scientific Purposes. National Advisory Committee for Laboratory Animal Research(NACLAR); 2004. Available from: www3.ntu.edu.sg/ Research2/.../NACLAR-guide\%Z0Lines.pdf. Accessed July 28, 2021.

51. Subash A, Veeraraghavan G, Sali VK, Bhardwaj M, Vasanthi HR. Attenuation of inflammation by marine algae Turbinaria ornata in cotton pellet induced granuloma mediated by fucoidan like sulphated polysaccharide. Carbohydr Polym. 2016;151:1261-1268.

52. Rai U, Rawal A, Singh S. Evaluation of the anti-inflammatory effect of an anti-platelet agent crinumin on carrageenan-induced paw oedema and granuloma tissue formation in rats. Inflammopharmacology. 2018;26(3):769-778.

53. Hijazi MA, El-Mallah A, Aboul-Ela M, Ellakany A. Evaluation of analgesic activity of Papaver libanoticum extract in mice: involvement of opioids receptors. Evid Based Compl Alter Med. 2017;2017: Article ID 8935085.

54. Lee JH, Kim YS, Song KS, et al. Biopersistence of silver nanoparticles in tissues from Sprague-Dawley rats. Part Fibre Toxicol. 2013;10(1):36.

55. Li RW, Lin GD, Myers SP, Leach DN. Anti-inflammatory activity of Chinese medicinal vine plants. J Ethnopharmacol. 2003;85(1):61-67.

56. Ahmad A, Wei Y, Syed F, et al. Isatis tinctoria mediated synthesis of amphotericin B-bound silver nanoparticles with enhanced photoinduced antileishmanial activity: a novel green approach. J Photochem Photobiol B. 2016;161:17-24.

57. Ahn E-Y, Jin H, Park Y. Assessing the antioxidant, cytotoxic, apoptotic and wound healing properties of silver nanoparticles greensynthesized by plant extracts. Mater Sci Eng C. 2019;101:204-216.

58. Wypij M, Czarnecka J, Świecimska M, Dahm H, Rai M, Golinska P. Synthesis, characterization and evaluation of antimicrobial and cytotoxic activities of biogenic silver nanoparticles synthesized from Streptomyces xinghaiensis OF1 strain. World J Microbiol Biotechnol. 2018;34(2):23.

59. Li G, Liu L, Sun Y, Liu H. Ecofriendly synthesis of silver-carboxy methyl cellulose nanocomposites and their antibacterial activity. $J$ Cluster Sci. 2018;29(6):1193-1199.

60. Hassabo AG, Nada AA, Ibrahim HM, Abou-Zeid NY. Impregnation of silver nanoparticles into polysaccharide substrates and their properties. Carbohydr Polym. 2015;122:343-350.

61. Asghar MA, Yousuf RI, Shoaib MH, Asghar MA, Mumtaz N. A review on toxicity and challenges in transferability of surface-functionalized metallic nanoparticles from animal models to humans. Biointegration. 2021;1-10.

62. Ali SW, Rajendran S, Joshi M. Synthesis and characterization of chitosan and silver loaded chitosan nanoparticles for bioactive polyester. Carbohydr Polym. 2011;83(2):438-446.

63. Hajji S, Khedir SB, Hamza-Mnif I, et al. Biomedical potential of chitosan-silver nanoparticles with special reference to antioxidant, antibacterial, hemolytic and in vivo cutaneous wound healing effects. Biochimica Et Biophysica Acta (BBA)-General Subjects. 2019;1863 (1):241-254.

64. Suteewong T, Wongpreecha J, Polpanich D, Jangpatarapongsa K, Kaewsaneha C, Tangboriboonrat P. PMMA particles coated with chitosan-silver nanoparticles as a dual antibacterial modifier for natural rubber latex films. Colloids Surf B Biointerfaces. 2019;174:544552 . 
65. Cakić M, Glišić S, Nikolić G, Nikolić GM, Cakić K, Cvetinov M. Synthesis, characterization and antimicrobial activity of dextran sulphate stabilized silver nanoparticles. J Mol Struct. 2016;1110:156161.

66. Sun D, Kang S, Liu C, Lu Q, Cui L, Hu B. Effect of zeta potential and particle size on the stability of $\mathrm{SiO} 2$ nanospheres as carrier for ultrasound imaging contrast agents. Int J Electrochem Sci. 2016;11 (10):8520-8529.

67. Jyoti K, Baunthiyal M, Singh A. Characterization of silver nanoparticles synthesized using Urtica dioica Linn. leaves and their synergistic effects with antibiotics. J Rad Res Appl Sci. 2016;9(3):217-227.

68. Reidy B, Haase A, Luch A, Dawson KA, Lynch I. Mechanisms of silver nanoparticle release, transformation and toxicity: a critical review of current knowledge and recommendations for future studies and applications. Materials. 2013;6(6):2295-2350.

69. Kim S-H, Lee H-S, Ryu D-S, Choi S-J, Lee D-S. Antibacterial activity of silver-nanoparticles against Staphylococcus aureus and Escherichia coli. Korean J Microbiol Biotechnol. 2011;39(1):77-85.

70. Pellieux C, Dewilde A, Pierlot C, Aubry J-M. [18] Bactericidal and virucidal activities of singlet oxygen generated by thermolysis of naphthalene endoperoxides. In: Packer L, Sies H, editors. Methods in Enzymology. Vol. 319. Elsevier; 2000:197-207.

71. Habibipour R, Moradi-Haghgou L, Farmany A. Green synthesis of AgNPs@PPE and its Pseudomonas aeruginosa biofilm formation activity compared to pomegranate peel extract. Int $J$ Nanomedicine. 2019;14:6891.

72. Perelshtein I, Ruderman E, Perkas N, et al. Chitosan and chitosanZnO-based complex nanoparticles: formation, characterization, and antibacterial activity. J Mater Chem B. 2013;1(14):1968-1976.

73. Tang R, Yu Z, Zhang Y, Qi C. Synthesis, characterization, and properties of antibacterial dye based on chitosan. Cellulose. 2016;23(3):1741-1749.

74. Zhao J, Maitituersun A, Li C, Li Q, Xu F, Liu T. Evaluation on analgesic and anti-inflammatory activities of total flavonoids from Juniperus sabina. Evid Based Compl Alter Med. 2018;2018.

75. David L, Moldovan B, Vulcu A, et al. Green synthesis, characterization and anti-inflammatory activity of silver nanoparticles using European black elderberry fruits extract. Colloids Surf $B$ Biointerfaces. 2014;122:767-777.

76. Govindappa M, Hemashekhar B, Arthikala M-K, Rai VR, Ramachandra Y. Characterization, antibacterial, antioxidant, antidiabetic, anti-inflammatory and antityrosinase activity of green synthesized silver nanoparticles using Calophyllum tomentosum leaves extract. Results Phys. 2018;9:400-408.

77. Zhang Z-B, Luo -D-D, Xie J-H, et al. Curcumin's metabolites, tetrahydrocurcumin and octahydrocurcumin, possess superior anti-inflammatory effects in vivo through suppression of TAK1-NF-kB pathway. Front Pharmacol. 2018;9:1181.

78. Azevedo LF, da Silva SM, Navarro LB, et al. Evidence of antiinflammatory and antinociceptive activities of Plinia edulis leaf infusion. J Ethnopharmacol. 2016;192:178-182.

79. Ur Rashid H, Xu Y, Ahmad N, Muhammad Y, Wang L. Promising anti-inflammatory effects of chalcones via inhibition of cyclooxygenase, prostaglandin E2, inducible NO synthase and nuclear factor $\mathrm{\kappa B}$ activities. Bioorg Chem. 2019;87:335-365.

80. Hebeish A, El-Rafie M, El-Sheikh M, Seleem AA, El-Naggar ME. Antimicrobial wound dressing and anti-inflammatory efficacy of silver nanoparticles. Int J Biol Macromol. 2014;65:509-515.

81. El Morsy EM, Ahmed MA. Carvedilol attenuates 1-arginine induced acute pancreatitis in rats through modulation of oxidative stress and inflammatory mediators. Chem Biol Interact. 2020;327:109181.
82. Jin L, Zeng W, Zhang F, Zhang C, Liang W. Naringenin ameliorates acute inflammation by regulating intracellular cytokine degradation. $J$ Immunol. 2017;199(10):3466-3477.

83. Vijayakumar S, Malaikozhundan B, Saravanakumar K, Durán-Lara EF, Wang M-H, Vaseeharan B. Garlic clove extract assisted silver nanoparticle-Antibacterial, antibiofilm, antihelminthic, anti-inflammatory, anticancer and ecotoxicity assessment. $J$ Photochem Photobiol B. 2019;198:111558.

84. Kumar V, Singh S, Srivastava B, Bhadouria R, Singh R. Green synthesis of silver nanoparticles using leaf extract of Holoptelea integrifolia and preliminary investigation of its antioxidant, antiinflammatory, antidiabetic and antibacterial activities. $J$ Environ Chem Eng. 2019;7(3):103094.

85. Jebali A, Kazemi B. Nano-based antileishmanial agents: a toxicological study on nanoparticles for future treatment of cutaneous leishmaniasis. Toxicol in Vitro. 2013;27(6):1896-1904.

86. Allahverdiyev AM, Abamor ES, Bagirova M, et al. Antileishmanial effect of silver nanoparticles and their enhanced antiparasitic activity under ultraviolet light. Int J Nanomedicine. 2011;6:2705.

87. Horta MF, Mendes BP, Roma EH, et al. Reactive oxygen species and nitric oxide in cutaneous leishmaniasis. J Parasitol Res. 2012;2012: Article ID 203818.

88. Song Z, Wu Y, Wang H, Han H. Synergistic antibacterial effects of curcumin modified silver nanoparticles through ROS-mediated pathways. Mater Sci Eng C. 2019;99:255-263.

89. Siritongsuk P, Hongsing N, Thammawithan S, et al. Two-phase bactericidal mechanism of silver nanoparticles against Burkholderia pseudomallei. PLoS One. 2016;11(12):e0168098.

90. Hazeem LJ, Kuku G, Dewailly E, et al. Toxicity effect of silver nanoparticles on photosynthetic pigment content, growth, ROS production and ultrastructural changes of microalgae Chlorella vulgaris. Nanomaterials. 2019;9(7):914.

91. Matés JM, Sánchez-Jiménez FM. Role of reactive oxygen species in apoptosis: implications for cancer therapy. Int J Biochem Cell Biol. 2000;32(2):157-170.

92. Sentürker S, Karahalil B, Inal M, et al. Oxidative DNA base damage and antioxidant enzyme levels in childhood acute lymphoblastic leukemia. FEBS Lett. 1997;416(3):286-290.

93. Poprac P, Jomova K, Simunkova M, Kollar V, Rhodes CJ, Valko M. Targeting free radicals in oxidative stress-related human diseases. Trends Pharmacol Sci. 2017;38(7):592-607.

94. Watal G, Watal A, Rai PK, Rai DK, Sharma G, Sharma B. Biomedical applications of nano-antioxidant. Oxidative Stress Nanotechnol. 2013;147-151.

95. Sridhar K, Charles AL. In vitro antioxidant activity of Kyoho grape extracts in DPPH and ABTS assays: estimation methods for EC50 using advanced statistical programs. Food Chem. 2019;275:41-49.

96. Zangeneh MM, Joshani Z, Zangeneh A, Miri E. Green synthesis of silver nanoparticles using aqueous extract of Stachys lavandulifolia flower, and their cytotoxicity, antioxidant, antibacterial and cutaneous wound-healing properties. Appl Organomet Chem. 2019;33(9):e5016.

97. Al-Shmgani HS, Mohammed WH, Sulaiman GM, Saadoon AH. Biosynthesis of silver nanoparticles from Catharanthus roseus leaf extract and assessing their antioxidant, antimicrobial, and woundhealing activities. Artif Cells, Nanomed Biotechnol. 2017;45 (6):1234-1240.

98. Chinnasamy G, Chandrasekharan S, Bhatnagar S. Biosynthesis of silver nanoparticles from Melia azedarach: enhancement of antibacterial, wound healing, antidiabetic and antioxidant activities. Int $J$ Nanomedicine. 2019;14:9823. 


\section{Publish your work in this journal}

The International Journal of Nanomedicine is an international, peerreviewed journal focusing on the application of nanotechnology in diagnostics, therapeutics, and drug delivery systems throughout the biomedical field. This journal is indexed on PubMed Central, MedLine, CAS, SciSearch ${ }^{\mathbb{B}}$, Current Contents ${ }^{\mathbb{B}} /$ Clinical Medicine,
Journal Citation Reports/Science Edition, EMBase, Scopus and the Elsevier Bibliographic databases. The manuscript management system is completely online and includes a very quick and fair peer-review system, which is all easy to use. Visit http://www.dovepress.com/ testimonials.php to read real quotes from published authors. 